\title{
High-resolution whole-genome analysis of sister-chromatid
}

\section{cohesion}

Elena Espinosa ${ }^{1}$, Evelyne Paly ${ }^{1}$ and François-Xavier Barre ${ }^{1 *}$

${ }^{1}$ Institute for Integrative Biology of the Cell (I2BC), Université Paris-Saclay, CEA, CNRS, Université Paris Sud, 1 Avenue de la Terrasse, 91198 Gif-sur-Yvette, France

*Correspondence to: $\underline{\text { francois-xavier.barre@,i2bc.paris-saclay.fr }}$

\begin{abstract}
Sister-chromatid cohesion describes the orderly association of newly-replicated DNA molecules behind replication forks. It plays an essential role in the maintenance and the faithful transmission of genetic information. It is created by DNA topological links and proteinaceous bridges, whose formation and deposition could be potentially affected by many different DNAbinding proteins. However, a mean to analyse local variations in the duration of cohesion on a whole genome was lacking. Here, we present a High-throughput methodology to monitor Sister Chromatid Contacts (Hi-SC2), and show that it permits to analyse locus-specific variations in sister-chromatid cohesion over the whole length of chromosomes.
\end{abstract}




\section{Introduction}

During replication, sister DNA copies are orderly associated by the formation of DNA topological links and proteinaceous bridges. The phenomenon is referred to as sister-chromatid cohesion. Cohesion facilitates homology search for recombinational repair and ensures that sister chromatids are suitably positioned for segregation (Kleckner et al., 2014; Morales and Losada, 2018). Fluorescence microscopy observations of bulk DNA and of a limited number of genomic positions in a few cellular models suggested that the duration of cohesion varied according to genomic position (Espeli et al., 2008; Fisher et al., 2013; Javer et al., 2013; Kleckner et al., 2004). However, the amount of time necessary to label a given genomic position to observe its replication and segregation dynamics using live fluorescence microscopy and the limited spatial resolution of fluorescence imaging prevents whole-genome high-resolution analyses of the relative cohesiveness of sister DNA copies.

Here, we present a High-throughput methodology to monitor Sister Chromatid Contacts (Hi$\mathrm{SC} 2$ ), which can be used to analyse locus-specific variations in sister-chromatid cohesion over the whole length of chromosomes at a high resolution. As a proof of principle, we applied it to Vibrio cholerae, the agent of the deadly human disease cholera, which is closely related to Escherichia coli in the phylogenetic tree of life, the only organism in which cohesion was so far extensively investigated (Bates and Kleckner, 2005; Joshi et al., 2013; Stouf et al., 2013). $V$. cholerae carries homologues of most of the chromosome replication, maintenance and segregation machineries of $E$. coli (Heidelberg et al., 2000). However, its genome is divided on two circular chromosomes, Chr1 and Chr2, whereas E. coli harbours a single chromosome (Trucksis et al., 1998; Yamaichi et al., 1999). Chr1 derives from the mono-chromosomal ancestor of E. coli and $V$. cholerae whereas $\mathrm{Chr} 2$ derives from a domesticated mega-plasmid. Nevertheless, the organisation and positioning of $\mathrm{Chr} 2$ participate to the cell cycle of the bacterium (Galli et al., 2016). Chr1 and Chr2 harbour a single origin of bi-directional 
replication, ori1 and ori2, respectively. Replication terminates in a region opposite of their origin, next to a site dedicated to the resolution of topological problems due to their circularity, difl and dif2, respectively (Galli et al., 2019; Val et al., 2008). Most strains of V. cholerae are not pathogenic or only cause local outbreaks of gastroenteritis. Epidemic strains have so far been found in only 2 out of $>200$ possible somatic O-antigens serogroups (Chatterjee and Chaudhuri, 2003). Epidemic strains are characterized by the capacity to produce cholera toxin, which is responsible for the deadly diarrhoea associated with the disease, and Type IV toxincoregulated pili (TCP), which are essential for small intestine colonization (Herrington et al., 1988). Both virulence factors are acquired by horizontal gene transfer. Cholera toxin is encoded in the genome of a lysogenic phage, СТХФ (Waldor and Mekalanos, 1996), which almost always integrates behind a Toxin Linked Cryptic satellite phage, TLC $\Phi$, at the difl locus (Hassan et al., 2010; Midonet et al., 2019). TCP is encoded in a $39.5 \mathrm{kbp}$ vibrio pathogenicity island inserted in Chr1, VPI-1. In addition to its role in intestine colonization, TCP serves as a receptor for CTXФ (Davis and Waldor, 2003). Hi-SC2 revealed that cohesion is highly prolonged in large genomic territories centred on the origin and terminus of replication of Chr1 and Chr2. It further revealed that the H-NS nucleoid-structuring protein, which acts as a transcriptional repressor in horizontally-acquired elements (Dorman, 2007), dramatically extends the duration of cohesion within VPI-1 and the O-antigen region (Ayala et al., 2015; Chun et al., 2009; Herrington et al., 1988). Finally, Hi-SC2 unveiled small locus-specific variations in the duration of cohesion over the whole length of each of the two Vibrio cholerae chromosomes, which had so far escaped scrutiny.

\section{Results}

\section{Hi-SC2 design}

Hi-SC2 exploits paired-end deep-sequencing to determine in parallel the status and position of sister-chromatid contact (SC2) reporters inserted at random positions in a library of cells 
(Figure 1A). The SC2 reporters are site-specific recombination cassettes. They consist of a very short DNA segment flanked by two directly-repeated site-specific recombination (SSR) sites. The small distance between the SSR sites prevents intramolecular recombination, which would excise the DNA segment separating the SSR sites and leave a single SSR site as a scar. However, intermolecular recombination events between sister copies of a reporter can also lead to the replacement of a cassette by a single SSR site (Demarre et al., 2014; Lesterlin et al., 2012). Hence, the frequency of replacement of a reporter by a single SSR site, $\boldsymbol{f}_{\boldsymbol{S C 2}}$, reflects the frequency of contacts between sister chromatids at its position of insertion, which can be used as a measure of the duration of cohesion (Figure 1A). In brief, Hi-SC2 starts with the introduction of a conditional expression allele of site-specific recombinase in a cell line and the creation of a library of cells harbouring a cognate SC2 reporter at random genomic positions by transposition. Production of the SSR is induced for different lengths of time during cell growth and/or at specific stages of the cell cycle. High-throughput paired-end sequencing is then used to determine the position and recombination status of the SC2 reporters.

\section{Analysis of Sister-Chromatid Cohesion in $V$. cholerae}

As a proof of principle, we applied Hi-SC2 to $V$. cholerae. To this end, we equipped an El Tor N16961 $V$. cholerae strain with an inducible allele of the tyrosine recombinase of phage P1, Cre, which acts on a $34 \mathrm{bp}$ SSR site, loxP. We inserted a SC2 reporter consisting of two directly repeated $\operatorname{lox} P$ sites separated by $21 \mathrm{bp}$ in a Mariner transposon specifically designed for efficient Tn-seq analysis (van Opijnen et al., 2009). We created cell libraries containing $>10^{5}$ independent transposition events, which corresponds to an average of $>1$ reporter every $40 \mathrm{bp}$ (Table S1). A total number of $10^{7}$ paired-end sequencing reads was sufficient to obtain a mean number of $>100$ reads per reporter position, which permitted to calculate $\boldsymbol{f}_{\boldsymbol{S C 2}}$ at most (if not all) reporter positions (Figure S1). $\boldsymbol{f}_{\boldsymbol{S C 2}}$ can be analysed at different scales of precision (Figure S2). For the purpose of the present work, we calculated the mean of $\boldsymbol{f}_{\boldsymbol{S C} 2}$ over $10 \mathrm{kbp}$ sliding- 
windows, which permits to highlight both short-range and long-range variations in cohesion along the two $V$. cholerae chromosomes in a small figure (Figure S2). By convention, we present the $\boldsymbol{f}_{\boldsymbol{S C 2}}$ profile of each chromosome in a clockwise orientation starting from their origin of replication (Figure 1B).

Before Cre production, we didn't observe any replacement of the SC2 reporter cassette by a single SSR site, demonstrating that such events exclusively resulted from Cre-mediated recombination (Figure $\left.1 \mathrm{~B}, 0^{\prime}\right) . \boldsymbol{f}_{\boldsymbol{S C 2}}$ increased as a function of time after the induction of Cre production (Figure 1B). It was not constant along the length of the genome, reaching a maximum of $\sim 70 \%$ after $90^{\prime}$ in slow growth conditions (Figure 1B). Higher frequencies were obtained at the same time in fast growth conditions, as expected because of the higher number of replication cycles (Figure S3A and B). Independent Cre-based SC2 reporter libraries yielded identical $\boldsymbol{f}_{\boldsymbol{S C} 2}$ profiles, demonstrating the reproducibility of the technique (Figure S3C and D). By comparison, the excision of a long loxP-cassette, which permits Cre-mediated intramolecular recombination, was constant over the whole genome and reached a frequency of $80 \%$ in only 30 ' of induction in slow growth, demonstrating that $\boldsymbol{f}_{S C 2}$ profiles were not due to differences in the accessibility of DNA and/or the activity of Cre along the genome (Figure S4).

\section{Cohesion is extended in large territories centred on ori1, ori2, dif1 and dif2}

$\boldsymbol{f}_{\boldsymbol{S C 2}}$ was strikingly elevated in four large $200 \mathrm{kbp}$ genomic territories centred on the replication origin and replication terminus of each of the two $V$. cholerae chromosomes, indicating that sister copies of these regions remained cohesive for a longer period of time than sister copies of the rest of the chromosome replication arms (Figure 1, Figure S3 and S5). $\boldsymbol{f}_{\boldsymbol{S C} \mathbf{2}}$ was maximal near dif1 and dif2, (Figure 1B, Figure S3 and S5). It reached up to 70\% at these positions after 90' of induction in slow growth conditions, while it was only in the order of $20 \%$ in the flanking regions (Figure 1B, Figure S3 and S5). The extensive cohesion of the difl-terrirory fits with 
previous fluorescence microscopy observations, which suggested that sister difl copies remained associated until the initiation of septum constriction (David et al., 2014; Demarre et al., 2014; Galli et al., 2017). However, sister copies of dif2, which is replicated at the same time of the cell cycle as difl, were found to split ahead of the initiation of septum constriction, in apparent contradiction with the Hi-SC2 data (Demarre et al., 2014; Galli et al., 2019). To resolve this issue, we analysed sister-chromatid contacts at the time of cell division using a reporter based on a site-specific recombination machinery whose activity is restricted to the time of constriction, Xer (Demarre et al., 2014; Kennedy et al., 2008; Val et al., 2008). Xerbased $\boldsymbol{f}_{\boldsymbol{S C} 2}$ was null at all genomic positions but in the immediate vicinity of difl and dif2, in agreement with the ordered choreography of segregation of Chr1 and $\mathrm{Chr} 2$ and the temporal restriction of the activity of Xer (Figure 2). It remained very low over the whole dif2-territory, including the dif2 position (Figure 2). It was also low in most of the difl-territory, apart from the immediate proximity of difl, where it was as high as Cre-based $\boldsymbol{f}_{\boldsymbol{S C 2} \mathbf{2}}$ (Figure 2). Taken together, these results suggest that sister copies of the origin and terminus regions of the two $V$. cholerae chromosomes are highly cohesive behind the replication forks and that most of the links between sister copies of genomic positions within the difl-and dif2-territories are released prior to the initiation of cell division, with the exception of the immediate vicinity of difl (Figure 2).

\section{VPI-1 creates a highly cohesive territory}

Hi-SC2 further revealed the existence of a large $200 \mathrm{kbp}$ territory in the middle of the left replication arm of Chr1 where $\boldsymbol{f}_{\boldsymbol{S C 2}}$ was elevated (Figure 3A and Figure S3D). This domain is centred on VPI-1. Deletion of VPI-1 supressed the elevated $\boldsymbol{f}_{\boldsymbol{S C} 2}$ within the whole territory, without affecting $\boldsymbol{f}_{\boldsymbol{S C 2}}$ in the rest of the genome (Figure 3A and Figure S6). These results prompted us to use fluorescence microscopy to inspect the segregation of a locus within the VPI-1 territory, L1, with respect to the segregation of a locus immediately downstream of it on 
the same replication arm, L2 (Figure 3B). As a comparison, we analysed the relative segregation of two genomic positions in the right replication arm, R1 and R2, which are located at approximately the same distance from ori1 than L1 and L2, but had equivalent $\boldsymbol{f}_{\boldsymbol{S C 2}}$ values (Figure 3B). We observed more cells with two R1 foci and a single R2 focus than cells with a single R1 focus and two R2 foci, as expected from the earlier replication of R1 (Figure 3B, left panel). In contrast, there were more cells with a single L1 focus and two L2 foci than cells with two L1 foci and a single L2 focus, demonstrating that the separation of sister L1 copies was delayed compared to the separation of sister L2 copies, as predicted by Hi-SC2 (Figure 3B, middle panel). Furthermore, we found that deletion of VPI-1 alleviated the segregation delay of sister L1 copies (Figure 3B, right panel). Together, these results demonstrate that VPI-1 creates a highly cohesive territory.

\section{The Histone-like Nucleoid Structuring protein promotes cohesion}

The Histone-like Nucleoid Structuring protein, H-NS, acts as a transcriptional repressor in horizontally-acquired elements (Dorman, 2007). It regulates the virulence of $V$. cholerae and covers the VPI-1 and O-antigen regions (Figure 4, bottom panel; Ayala et al., 2015; Chun et al., 2009; Herrington et al., 1988). Deletion of hns suppressed sister-chromatid cohesion within the $100 \mathrm{kbp}$ origin-proximal part of the VPI-1 territory and the O-antigen region without affecting surrounding regions, demonstrating that H-NS is a region-specific cohesion factor (Figure 4 and Figure S7).

\section{Hi-SC2 unveiled small locus-specific variations in the duration of cohesion}

Small short-distance $(<10 \mathrm{kbp})$ fluctuations in the Hi-SC2 profiles are superimposed on the large long-distance $\boldsymbol{f}_{\boldsymbol{S C} \mathbf{2}}$ variations (Figure 1B, Figure S2). Independent Cre-based SC2 reporter libraries yielded identical short-distance $\boldsymbol{f}_{\boldsymbol{S C} 2}$ variations, indicating that they were not due to experimental noise (Figure S3C, S6 and S7). Furthermore, short-distance $\boldsymbol{f}_{\boldsymbol{S C 2}}$ variations changed depending on the growth conditions, indicating that they were linked to physiological 
parameters (Figure S3A). Taken together, these results suggest that short-distance $\boldsymbol{f}_{\boldsymbol{S C} \mathbf{2}}$ variations probably reflect small locus-specific differences in the duration of cohesion over the whole length of chromosomes, which couldn't be explored with current fluorescence microscopy techniques.

\section{Discussion}

Sister-Chromatid Cohesion plays an essential role in the maintenance and the faithful transmission of genetic information. Previous work suggested that many different DNAbinding proteins could affect cohesion. However, the duration of cohesion was only characterized in detail at a limited number of genomic positions in a few model organisms. The Hi-SC2 methodology we describe here offers the possibility to analyse local variations in the duration of cohesion at a high resolution over a whole genome (Figure 1). It gives a massive amount of information, but data analysis and representation are relatively simple. The methodology can be used to monitor the relative amount of time during which sister DNA copies remain cohesive during the entire cell cycle (Figure 1) or to analyse cohesion at specific stages of the cell cycle by placing the SC2 recombinase under an inducible promoter or choosing it for its specific cell-cycle regulation (Figure 2). Its application to $V$. cholerae demonstrated that cohesion is connected to other genome management processes, such as replication (Figure 2) and transcription regulation (Figure 3 and 4).

\section{Initiation and termination of replication take place in cohesive territories}

Hi-SC2 demonstrated that sister-chromatid cohesion is prolonged in 200kbp territories centred on the replication origin and replication terminus of each of the two $V$. cholerae chromosomes (Figure 2). Thus, Hi-SC2 opens up a new field of investigation on the relationship between the formation of these highly cohesive territories, the actual replication process and the regulation of replication in different bacterial and eukaryotic models.

\section{Cohesion is released before the actual repositioning of sister copies}


Fluorescence microscopy showed that sister copies of the origin region of the E. coli chromosome are highly cohesive (Bates and Kleckner, 2005; Joshi et al., 2013). We could have expected cohesion at the origin region of the $V$. cholerae chromosomes to be more limited than cohesion at the origin of the E. coli chromosome because the $V$. cholerae chromosomes, as most other bacterial chromosomes and in contrast to the $E$. coli chromosome, are equipped with a partition machinery dedicated to the active segregation of sister origin copies (Fogel and Waldor, 2006; Yamaichi et al., 2007). The observation of the elevated cohesiveness of the replication origins of the $V$. cholerae chromosomes suggest that the partition machineries cannot release all of the cohesion links but only serve to assure the correct repositioning of sister origins in the cell after their individualisation.

Sister copies of the terminus region of the chromosome of slow growing E. coli cells were also proposed to be highly cohesive based on genetic experiments and fluorescence microscopy observations (Galli et al., 2017; Stouf et al., 2013). It was attributed to the requirement for the activity of a conserved ATP-dependent DNA pump anchored in the division septum, FtsK, in sister termini separation (Stouf et al., 2013). However, FtsK is only active during septum closure (Demarre et al., 2014; Kennedy et al., 2008), whereas our Hi-SC2 results demonstrate that sister copies of the terminus region of Chr2 and of the major part of the terminus region of Chrl are separated before the initiation of constriction (Figure 2). This observation suggests that FtsK does not participate in the release of cohesion at the terminus of the $V$. cholerae chromosomes but only serve to assure their faithful distribution in opposite daughter cell compartments.

Taken together, these results suggest that segregation is a multi-step process, with release of cohesion and condensation driving the individualisation of sister copies before their active repositioning in the cell, as proposed in eukaryotes.

Transcription regulation programs can promote cohesion 
Hi-SC2 revealed that VPI-1 created a highly cohesive territory in the middle of the left replication arm of Chr1 (Figure 3). VPI-1 is a major pathogenic island of $V$. cholerae, which was known to be regulated by H-NS. Deletion of H-NS alleviated the cohesiveness of sister DNA copies within VPI-1 and the origin proximal part of the highly cohesive territory surrounding it (Figure 4). Deletion of H-NS also reduced cohesion in the O-antigen region, even if this region is located in the origin domain of Chr1 (Figure 4). The implication of a bacterial repressor in cohesion creates a parallel with the action of cohesins in eukaryotes, which ensure sister-chromatid cohesion but also participate in the regulation of transcription via the formation of topologically associated domains (Uhlmann, 2008).

\section{Hi-SC2 unveiled small locus-specific variations in the duration of cohesion}

The Hi-SC2 methodology permits to monitor the relative frequency of contacts between sister copies at an unprecedented high resolution (Figure S3). It unveiled short-range locus-specific variations in cohesion, which could not be observed using fluorescence microscopy (Figure 14). We are attracted by the idea that small locus-specific $\boldsymbol{f}_{\boldsymbol{S C 2}}$ variations could be at the origin of the cyclic accumulation and relief of mechanical stress observed during the individualization of sister chromatids (Bates and Kleckner, 2005; Fisher et al., 2013). The Hi-SC2 methodology will permit to investigate the multiple factors at the origin of the local variations in cohesion along the length of chromosomes, including the local transcriptional status for the genomic positions, the proteins binding to them, their composition in bases and their methylation.

\section{Experimental Procedures}

Bacterial strains and growth conditions. Strains are listed in Extended Data Table 2. All $V$. cholerae strains were derivatives of El Tor N16961 (Heidelberg et al., 2000) and were constructed by natural transformation (Meibom et al., 2005). Plasmids used for the construction of strains are listed in Table S3. Strains were grown in LB at $37^{\circ} \mathrm{C}$ for fast growth conditions or M9 media supplemented with $0.2 \%$ fructose at $30^{\circ} \mathrm{C}$ for slow growth conditions. 
Cre- and Xer-based SC2 reporters. Cre and Xer are topologically independent recombinases, i.e. they can recombine sites belonging to different molecules, recombine sites directly repeated on the same molecule and sites in inverted orientations. The Cre- and Xer-based SC2 reporters consist of DNA cassettes flanked by two directly-repeated loxP or difl sites, respectively. The recombination sites were separated by $21 \mathrm{bp}$ in the case of loxP and $27 \mathrm{bp}$ in the case of dif to prevent their excision by intramolecular recombination.

Cre-activity reporter. The Cre-activity reporter consists of a DNA cassette flanked by two directly-repeated loxP sites separated by $205 \mathrm{bp}$. It is more than the persistence length of DNA, which permits excision by intramolecular recombination.

Tightly inducible Cre and Xer production alleles. To ensure no leaky production of Cre or Xer, the recombinase genes were placed under the control of the arabinose promoter $\left(\mathrm{P}_{\mathrm{BAD}}\right)$ and the E. coli lacZ promoter was inserted at the end of the gene in inverse orientation (invP $\mathrm{P}_{\text {lac }}$ ). Transcription from invP $\mathrm{P}_{\text {lac }}$ inhibits leaky transcription from $\mathrm{P}_{\mathrm{BAD}}$ in the absence of arabinose. IPTG was added to all cultures to ensure invP $\mathrm{P}_{\text {lac }}$ transcription before the time of induction of the recombinases. To further ensure no leaky production, the Cre and Xer production alleles were inserted as a single copy in the $V$. cholerae genome.

Reporter library construction. The Cre- and Xer-based SC2 reporters and the Cre-activity reporter were randomly inserted by transposition. The transposition plasmids used to insert the Cre- and Xer-based SC2 reporters and the Cre-activity reporter are derivatives of the pSWT23 suicide plasmid conjugation vector (Table S3; (Demarre et al., 2005)). They carry the transposase of the magellan5 Mariner transposon and a kanamycin resistance marker flanked by the inverted repeats of the transposon (Himar) in which a MmeI restriction site has been inserted to facilitate the analysis of the position of insertion of the kanamycin cassette by highthroughput sequencing (van Opijnen et al., 2009). The Rd2SP sequence (Illumina) was introduced downstream of the kanamycin resistance for sequencing purposes. The Cre- and 
Xer-based SC2 reporters and the Cre-activity reporter were cloned downstream of the Rd2SP sequence. The transposition vectors were introduced by conjugation as follows: donor (EE14 for the Cre-based SC2 reporter and Cre-activity reporter; EE6 for the Xer-based SC2 reporter) and recipient cells were grown for 16 hours at $37^{\circ} \mathrm{C}$ in LB. The donor was grown with DAP $(0.3 \mathrm{mM})$ and chloramphenicol $(25 \mu \mathrm{g} / \mathrm{ml})$ whereas the recipient was grown with zeocin $(25$ $\mu \mathrm{g} / \mathrm{ml})$ and IPTG $(0.1 \mathrm{mM}) .250 \mu \mathrm{l}$ of each culture were mixed, washed in LB with IPTG, resuspended into $30 \mu \mathrm{l}$ of LB with IPTG and placed into a $0.45 \mu \mathrm{m}$ filter (Millipore) in a LB agar plate supplemented with DAP and IPTG. Conjugation was carried out for 4 hours at 37 ${ }^{\circ} \mathrm{C}$. Thirty conjugations were performed per each library. After conjugations, cells were pooled together, resuspended in $6 \mathrm{ml}$ of LB with IPTG and plated on LB plates containing kanamycin $(50 \mu \mathrm{g} / \mathrm{ml})$ and IPTG. Plates were incubated for 16 hours at $30{ }^{\circ} \mathrm{C}$ except for EEV113 and EEV114, which were incubated for 40 hours. Cells were scraped, mixed together in LB with IPTG and stored in aliquots at $-80{ }^{\circ} \mathrm{C}$.

Sister-Chromatid Cohesion assays. Aliquots of the transposon library were thawed on ice and $\sim 10^{9}$ cells were diluted into $100 \mathrm{ml}$ of media supplemented with IPTG. Cells were grown until exponential phase $\left(\mathrm{OD}_{600} 0.2\right)$. Then, $\sim 10^{9}$ cells were centrifuged and transferred into $10 \mathrm{ml}$ of fresh media without IPTG. After 30 minutes, arabinose was added at a final concentration of $0.02 \% . \sim 10^{9}$ cells were recovered and frozen in liquid nitrogen at different time points after induction. For the essential gene analysis, cells were collected after 24 hours (FX409 and FX410 datasets).

Paired-end sequencing. Extraction of chromosomal DNA was performed using the Sigma GenElute bacterial genomic DNA kit. $2 \mu \mathrm{g}$ of DNA were digested for 4 hours with MmeI (NEB) following the manufacturer's instructions. Digested DNA was purified with MiniElute columns (Qiagen). The Pippinprep (SAGE science) was used to purify digested fragments of a length comprised between $800 \mathrm{bp}$ and $2 \mathrm{kbp}$, which corresponds to the region containing the 
transposon. $400 \mathrm{ng}$ of purified DNA was ligated overnight at $16^{\circ} \mathrm{C}$ to adapters (Table S4) with T4 DNA ligase (NEB). Ligated DNA was purified using MiniElute columns (Qiagen). For each library, 3 PCR reactions were performed using $2 \mu$ of ligated DNA as template and a pair of Illumina oligos (Table S4, P5 and P7). The PCR reactions were performed using the following parameters: $98{ }^{\circ} \mathrm{C}$ for 30 seconds, 17 cycles of $98^{\circ} \mathrm{C} 30$ seconds, $68^{\circ} \mathrm{C} 30$ seconds, $72{ }^{\circ} \mathrm{C} 30$ seconds and a final step of $72{ }^{\circ} \mathrm{C}$ for 7 minutes. PCR products were concentrated with a MiniElute columns (Qiagen) and purified using Pippinprep (SAGE science). Paired-end sequencing was performed on a NextSeq (Illumina).

Sequencing data analysis. First, barcodes and adapter sequences were removed from the sequences using Cutadapt version 1.9.1 (Martin, 2011). Second, Cutadapt was used to remove the transposon end sequence. Third, Cutadapt was used to select total reads and reads in which the reporter cassette had been excised. Finally, reads were aligned on the $V$. cholerae EEV29 genome with the BWA software (Li and Durbin, 2010).

Hi-SC2 analysis. Unless otherwise stated, $\boldsymbol{f}_{\boldsymbol{S C} 2}$ was calculated as the ratio between the number of single SSR sites over a $10 \mathrm{kbp}$ window around the position and the total number of transposition insertion in this window. Note, however, that $\boldsymbol{f}_{\boldsymbol{S C 2}}$ can also be analysed at the bp level. Points for which we recovered less than 500 reads, because the $10 \mathrm{kbp}$ window contains too many essential genes or repeated sequences were deleted (Figure S1). Hi-SC2 profiles were calculated using MatLab (Mathworks). Scripts are available on request.

Essential genes analysis. Essential genes and intergenic regions were determined using ARTIST (Pritchard et al., 2014). Results are shown in Table S6.

Fluorescence microscopy analysis. To confirm that the elevated frequency of cassette excision within the VPI-1 domain corresponded to a local increase in cohesion, we tagged a locus in the VPI-1 domain, just downstream of the pathogenicity island itself, L1, and a locus outside of the VPI-1 domain, L2, $80 \mathrm{kbp}$ downstream of L1. As a control, we tagged two loci on the right 
replication arm of $\mathrm{Chr} 1, \mathrm{R} 1$ and $\mathrm{R} 2$, at a similar distance from ori 1 than $\mathrm{L} 1$ and $\mathrm{L} 2$, respectively. Hi-SC2 analysis suggested that the cohesiveness of sister R1 and R2 copies were similar. L1 and R1 were tagged with a parSPMT1 site. L2 and R2 were tagged with a $3 \mathrm{kbp}$ lacO array. The positions and numbers of L1 and R1 foci were visualized with a ParBPMT1-YGFP fusion (David et al., 2014; Stouf et al., 2013) and the positions and numbers of L2 and R2 loci were visualized with a LacI-mCherry fusion (Lau et al., 2003). Differences in timing of segregation under slow growth were determined by calculating the proportion of cells displaying 1 YGFP and 1 mCherry foci (1:1), 2 YGFP and 1 mCherry foci (2:1), 1 YGFP and 2 mCherry foci (1:2) and 2 YGFP and 2 mCherry foci (2:2). Cells from the 1:1 and 2:2 categories are not informative. However, the proportion of cells belonging to the $2: 1$ and 1:2 categories reflect the difference in timing of separation of sister DNA copies at the two loci (Stouf et al., 2013). Cells from the 1:2 or $2: 1$ category are not very abundant, which imposed the analysis of $>1000$ cells. Cells were grown in M9 media supplemented with fructose as described in the reporter cassette excision assays. Cells were placed on an agarose pad (1\% w/v) (Ultrapure, Invitrogen). For snapshot analysis, cells images were acquired using a DM6000-B (Leica) fluorescence microscope equipped with an ORCA-Flash 4.0 camera (Hamamatsu) and piloted with MetaMorph (Version 7.8.8.0, Molecular Devices). They were analysed using MicrobeTracker (Sliusarenko et al., 2011).

Data and materials availability. Hi-SC2 Sequence data was deposited in the ArrayExpress Archive of Functional Genomics Data (https://www.ebi.ac.uk/arrayexpress/).

\section{Acknowledgements}

We thank C. Possoz, G. Lelandais, V. Lioy and Y. Yamaichi and the high-throughput sequencing facility of the I2BC. The work was supported by the ERC (FP7/2007-2013, grant number 28159) and the ANR (grants 2016-CE12-0030-0 and 2018-CE12-0012-03). 


\section{References}

Ayala, J.C., Wang, H., Benitez, J.A., and Silva, A.J. (2015). RNA-Seq analysis and whole genome DNA-binding profile of the Vibrio cholerae histone-like nucleoid structuring protein (H-NS). Genomics Data 5, 147-150.

Bates, D., and Kleckner, N. (2005). Chromosome and Replisome Dynamics in E. coli: Loss of Sister Cohesion Triggers Global Chromosome Movement and Mediates Chromosome Segregation. Cell 121, 899-911.

Chatterjee, S.N., and Chaudhuri, K. (2003). Lipopolysaccharides of Vibrio cholerae. I. Physical and chemical characterization. Biochim Biophys Acta 1639, 65-79.

Chun, J., Grim, C.J., Hasan, N.A., Lee, J.H., Choi, S.Y., Haley, B.J., Taviani, E., Jeon, Y.-S., Kim, D.W., Lee, J.H., et al. (2009). Comparative genomics reveals mechanism for short-term and long-term clonal transitions in pandemic Vibrio cholerae. Proc. Natl. Acad. Sci. U. S. A. 106, 15442-15447.

David, A., Demarre, G., Muresan, L., Paly, E., Barre, F.-X., and Possoz, C. (2014). The two Cis-acting sites, parS1 and oriC1, contribute to the longitudinal organisation of Vibrio cholerae chromosome I. PLoS Genet. 10, e1004448.

Davis, B.M., and Waldor, M.K. (2003). Filamentous phages linked to virulence of Vibrio cholerae. Curr. Opin. Microbiol. 6, 35-42.

Demarre, G., Guérout, A.-M., Matsumoto-Mashimo, C., Rowe-Magnus, D.A., Marlière, P., and Mazel, D. (2005). A new family of mobilizable suicide plasmids based on broad host range R388 plasmid (IncW) and RP4 plasmid $(\mathrm{IncP} \alpha)$ conjugative machineries and their cognate Escherichia coli host strains. Res. Microbiol. 156, $245-255$.

Demarre, G., Galli, E., Muresan, L., Paly, E., David, A., Possoz, C., and Barre, F.-X. (2014). Differential management of the replication terminus regions of the two Vibrio cholerae chromosomes during cell division. PLoS Genet. 10, e1004557.

Dorman, C.J. (2007). H-NS, the genome sentinel. Nat. Rev. Microbiol. 5, 157-161.

Espeli, O., Mercier, R., and Boccard, F. (2008). DNA dynamics vary according to macrodomain topography in the E. coli chromosome. Mol. Microbiol. 68, 1418-1427.

Fisher, J.K., Bourniquel, A., Witz, G., Weiner, B., Prentiss, M., and Kleckner, N. (2013). Four dimensional imaging of E. coli nucleoid organization and dynamics in living cells. Cell 153, 882-895.

Fogel, M.A., and Waldor, M.K. (2006). A dynamic, mitotic-like mechanism for bacterial chromosome segregation. Genes Dev 20, 3269-3282.

Galli, E., Poidevin, M., Le Bars, R., Desfontaines, J.-M., Muresan, L., Paly, E., Yamaichi, Y., and Barre, F.-X. (2016). Cell division licensing in the multi-chromosomal Vibrio cholerae bacterium. Nat. Microbiol. 1, 16094.

Galli, E., Midonet, C., Paly, E., and Barre, F.-X. (2017). Fast growth conditions uncouple the final stages of chromosome segregation and cell division in Escherichia coli. PLoS Genet. 13, e1006702.

Galli, E., Ferat, J.-L., Desfontaines, J.-M., Val, M.-E., Skovgaard, O., Barre, F.-X., and Possoz, C. (2019). Replication termination without a replication fork trap. Sci. Rep. 9, 8315.

Hassan, F., Kamruzzaman, M., Mekalanos, J.J., and Faruque, S.M. (2010). Satellite phage TLC $\varphi$ enables toxigenic conversion by CTX phage through dif site alteration. Nature 467, 982-985.

Heidelberg, J.F., Eisen, J.A., Nelson, W.C., Clayton, R.A., Gwinn, M.L., Dodson, R.J., Haft, D.H., Hickey, E.K., Peterson, J.D., Umayam, L., et al. (2000). DNA sequence of both chromosomes of the cholera pathogen Vibrio cholerae. Nature 406, 477-483. 
Herrington, D.A., Hall, R.H., Losonsky, G., Mekalanos, J.J., Taylor, R.K., and Levine, M.M. (1988). Toxin, toxincoregulated pili, and the toxR regulon are essential for Vibrio cholerae pathogenesis in humans. J. Exp. Med. 168, 1487-1492.

Javer, A., Long, Z., Nugent, E., Grisi, M., Siriwatwetchakul, K., Dorfman, K.D., Cicuta, P., and Lagomarsino, M.C. (2013). Short-time movement of E. coli chromosomal loci depends on coordinate and subcellular localization. Nat. Commun. 4, 1-8.

Joshi, M.C., Magnan, D., Montminy, T.P., Lies, M., Stepankiw, N., and Bates, D. (2013). Regulation of sister chromosome cohesion by the replication fork tracking protein SeqA. PLoS Genet. 9, e1003673.

Kennedy, S.P., Chevalier, F., and Barre, F.-X. (2008). Delayed activation of Xer recombination at dif by FtsK during septum assembly in Escherichia coli. Mol. Microbiol. 68, 1018-1028.

Kleckner, N., Zickler, D., Jones, G.H., Dekker, J., Padmore, R., Henle, J., and Hutchinson, J. (2004). A mechanical basis for chromosome function. Proc. Natl. Acad. Sci. U. S. A. 101, 12592-12597.

Kleckner, N., Fisher, J.K., Stouf, M., White, M.A., Bates, D., and Witz, G. (2014). The Bacterial Nucleoid: Nature, Dynamics and Sister Segregation. Curr. Opin. Microbiol. 22, 127.

Lau, I.F., Filipe, S.R., Søballe, B., Økstad, O.-A., Barre, F.-X., and Sherratt, D.J. (2003). Spatial and temporal organization of replicating Escherichia coli chromosomes. Mol. Microbiol. 49, 731-743.

Lesterlin, C., Gigant, E., Boccard, F., and Espéli, O. (2012). Sister chromatid interactions in bacteria revealed by a site-specific recombination assay. EMBO J. 31, 3468-3479.

Li, H., and Durbin, R. (2010). Fast and accurate long-read alignment with Burrows-Wheeler transform. Bioinformatics 26, 589-595.

Martin, M. (2011). Cutadapt removes adapter sequences from high-throughput sequencing reads. EMBnet.Journal $17,10-12$.

Meibom, K.L., Blokesch, M., Dolganov, N.A., Wu, C.Y., and Schoolnik, G.K. (2005). Chitin induces natural competence in Vibrio cholerae. Science 310, 1824-1827.

Midonet, C., Miele, S., Paly, E., Guerois, R., and Barre, F.-X. (2019). The TLC $\Phi$ satellite phage harbors a Xer recombination activation factor. Proc. Natl. Acad. Sci. 201902905.

Morales, C., and Losada, A. (2018). Establishing and dissolving cohesion during the vertebrate cell cycle. Curr. Opin. Cell Biol. 52, 51-57.

van Opijnen, T., Bodi, K.L., and Camilli, A. (2009). Tn-seq; high-throughput parallel sequencing for fitness and genetic interaction studies in microorganisms. Nat. Methods 6, 767-772.

Pritchard, J.R., Chao, M.C., Abel, S., Davis, B.M., Baranowski, C., Zhang, Y.J., Rubin, E.J., and Waldor, M.K. (2014). ARTIST: High-Resolution Genome-Wide Assessment of Fitness Using Transposon-Insertion Sequencing. PLoS Genet. 10.

Sliusarenko, O., Heinritz, J., Emonet, T., and Jacobs-Wagner, C. (2011). High-throughput, subpixel precision analysis of bacterial morphogenesis and intracellular spatio-temporal dynamics. Mol. Microbiol. 80, 612-627.

Stouf, M., Meile, J.-C., and Cornet, F. (2013). FtsK actively segregates sister chromosomes in Escherichia coli. Proc. Natl. Acad. Sci. U. S. A. 110, 11157-11162.

Trucksis, M., Michalski, J., Deng, Y.K., and Kaper, J.B. (1998). The Vibrio cholerae genome contains two unique circular chromosomes. Proc. Natl. Acad. Sci. U. S. A. 95, 14464-14469.

Uhlmann, F. (2008). Molecular biology: Cohesin branches out. Nature 451, 777-778. 
Val, M.-E., Kennedy, S.P., El Karoui, M., Bonné, L., Chevalier, F., and Barre, F.-X. (2008). FtsK-dependent dimer resolution on multiple chromosomes in the pathogen Vibrio cholerae. PLoS Genet. 4, e1000201.

Waldor, M.K., and Mekalanos, J.J. (1996). Lysogenic conversion by a filamentous phage encoding cholera toxin. Science 272, 1910-1914.

Yamaichi, Y., Iida, T., Park, K.-S., Yamamoto, K., and Honda, T. (1999). Physical and genetic map of the genome of Vibrio parahaemolyticus: presence of two chromosomes in Vibrio species. Mol. Microbiol. 31, 1513-1521.

Yamaichi, Y., Fogel, M.A., and Waldor, M.K. (2007). par genes and the pathology of chromosome loss in Vibrio cholerae. Proc. Natl. Acad. Sci. U. S. A. 104, 630-635. 
A
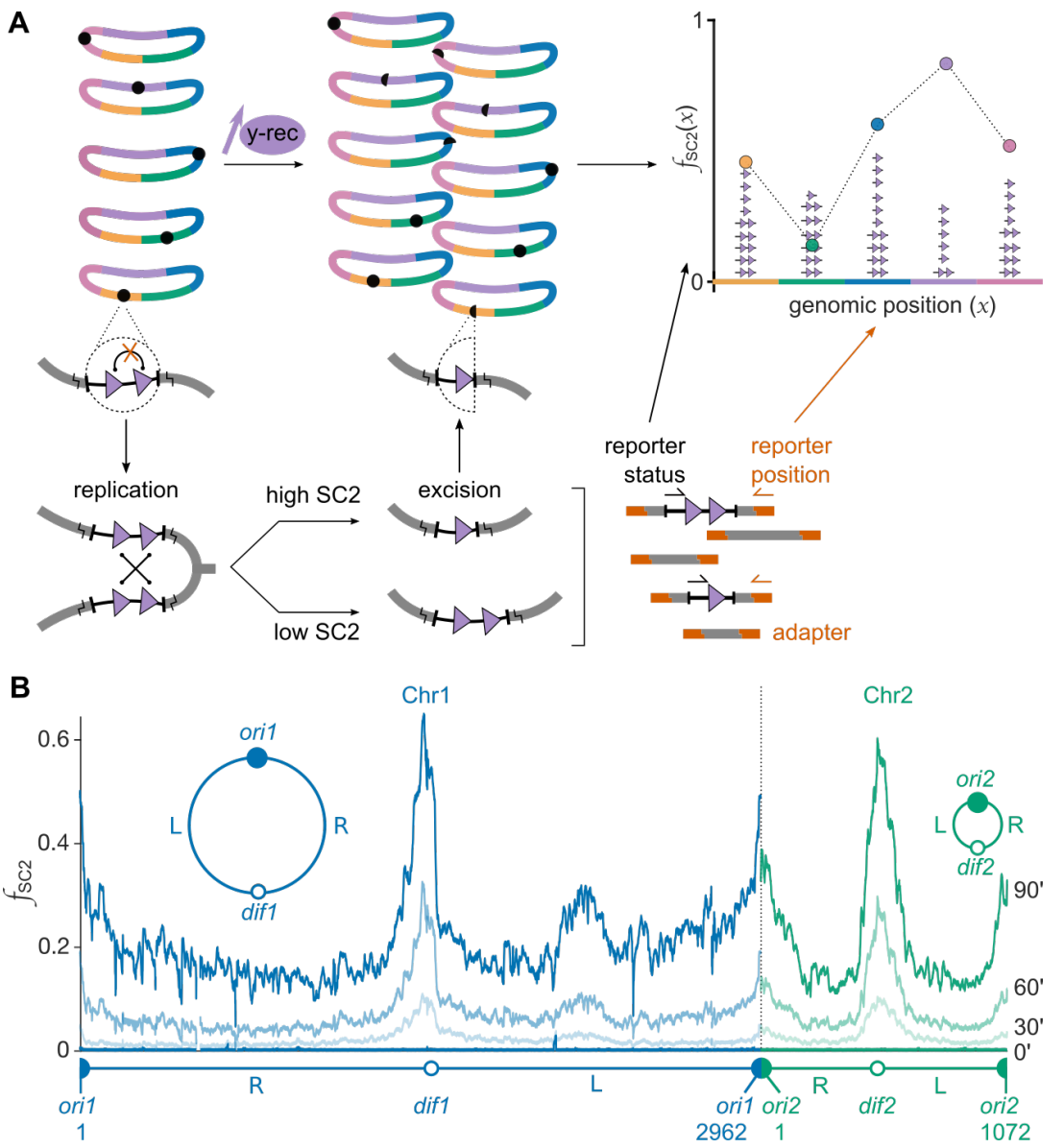

Figure 1. Overview of Hi-SC2. (A) Schematic representation of the assay: the SC2 reporter (black circle) consists of two directly repeated site-specific recombination (SSR) sites (purple triangles), separated by a very short piece of DNA. When the cognate tyrosine recombinase is produced (y-rec), recombination events between sister chromatids drive the replacement of the two SSR sites at the SC2 reporter position by a single one. High-throughput paired-end sequencing permits to determine the genomic position of the SC2 reporter (orange primer) and the number of SSR sites at this position (black primer). The proportion of single SSR sites to the total number of SC2 reporter inserted at a given genomic position, $\boldsymbol{x}$, reflects the frequency of sister-chromatid contacts at this position, $\boldsymbol{f}_{\boldsymbol{S C 2}}(\boldsymbol{x})$. (B) Cre-based $\boldsymbol{f}_{\boldsymbol{S C 2}}$ along $V$. cholerae Chr1 (blue lines) and Chr2 (green lines). Solid and open circles depict the origin and terminus of replication of the chromosome, respectively; the left and right replication arms are indicated as $\mathrm{L}$ and $\mathrm{R}$, respectively. Chromosome sizes are indicated in $\mathrm{kbp}$. 


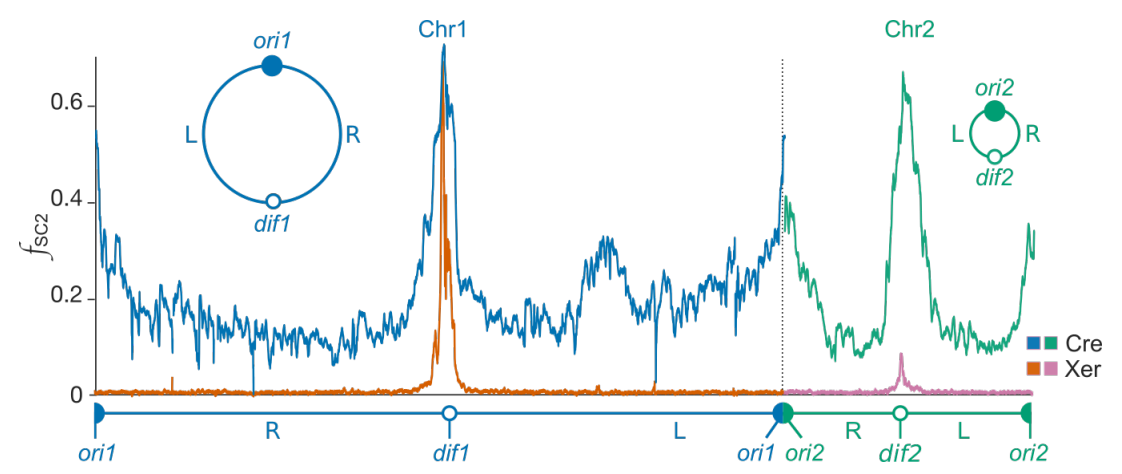

Figure 2. Relative cohesiveness of sister chromatids during cell division. Comparison of the Cre-based (FX224 dataset) and Xer-based (FX129 dataset) Hi-SC2 profiles. Cre permits to monitor $\boldsymbol{f}_{\boldsymbol{S C 2}}$ from the time of replication of a genomic position to the time of separation of the resulting sister copies. Xer permits to specifically monitor $\boldsymbol{f}_{\boldsymbol{S C 2}}$ during the final stage of cell division, septum constriction. 
A

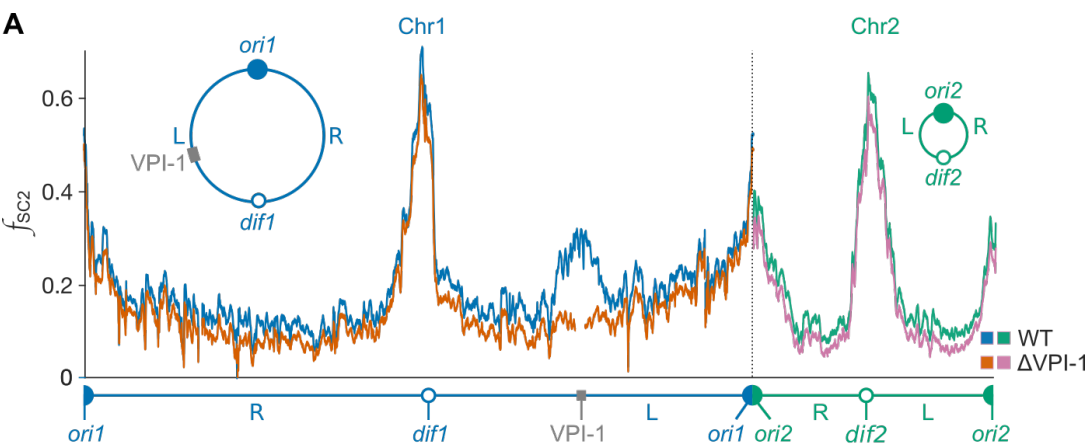

B
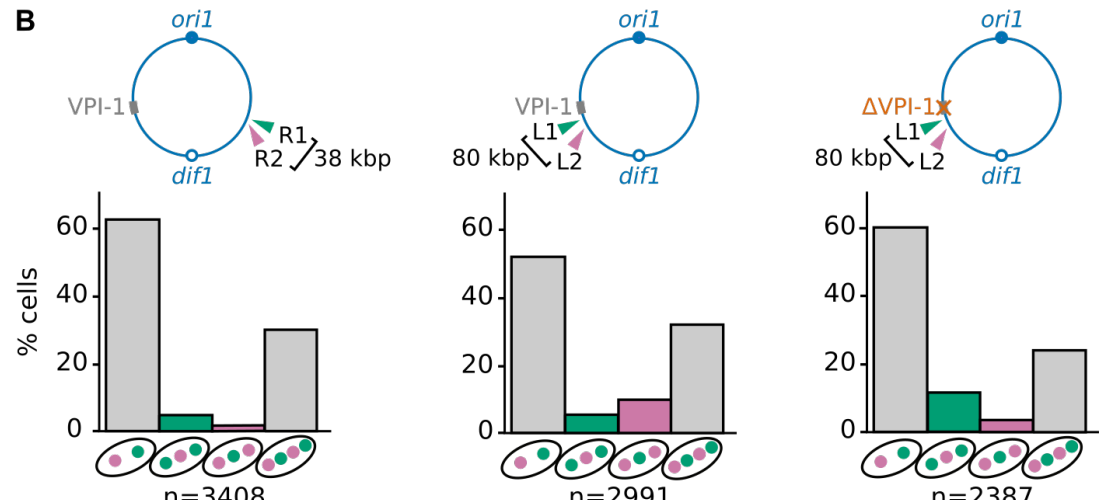

Figure 3. A highly cohesive territory surrounds the VPI-1 Vibrio pathogenicity island. (A)

Comparison of the Cre-based Hi-SC2 profiles in WT and $\triangle$ VPI-1 cells. The position of VPI-1 is indicated with a grey box (from bp 2176653 to bp 2217966 kbp). (B) Fluorescence microscopy analysis of the order of segregation of two neighbouring loci on the same replication arm. Origin- and terminus-proximal loci are depicted in green and purple, respectively. Graphs show the relative proportion of cells with the indicated number of foci. Informative cell categories are highlighted in colour. n: total number of analysed cells from two independent experiments. Distances between markers are indicated. 


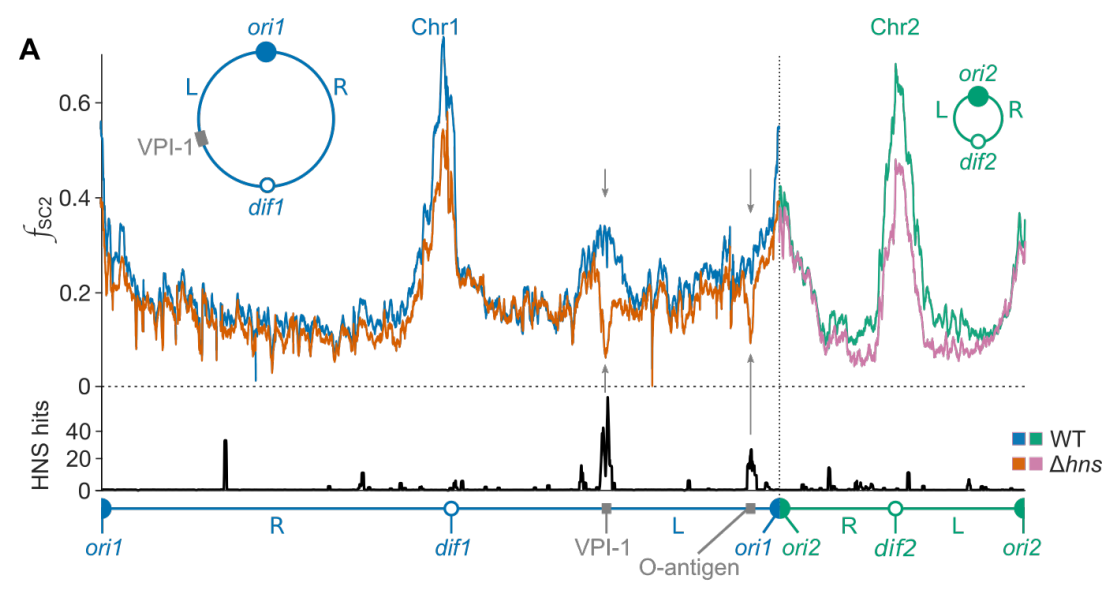

B
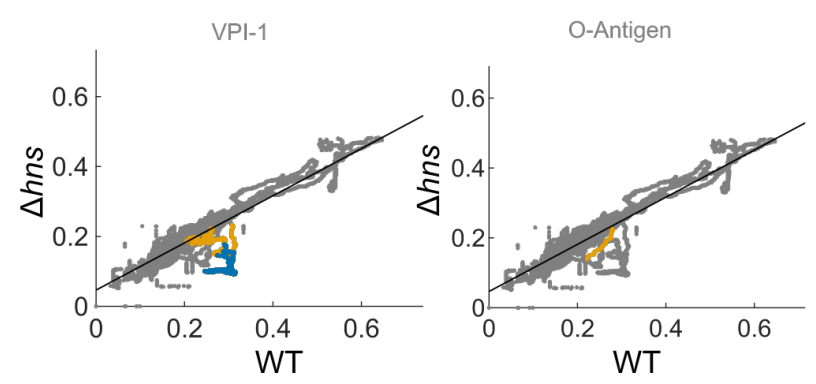

Figure 4. H-NS extends the cohesiveness of sister chromatids within VPI-1 and the Oantigen region. (A) Upper panel: Cre-based Hi-SC2 profiles in WT and $\Delta h n s$ cells; Lower panel: relative distribution of H-NS along the V. cholerae genome analysed by ChIPseq (Ayala et al., 2015). Grey arrows indicate regions of significantly lower SC2 frequencies in $\Delta h n s$ cells. (B) Correlation between the SC2-reporter cassette excision frequencies in $\Delta h n s$ (FX215 dataset) and WT cells (FX224 dataset). Black line: linear regression of the $\Delta h n s$ and WT data. Left panel: data points within VPI-1 and the 2160 to $2283 \mathrm{kbp}$ origin-proximal part of the VPI1 territory are highlighted in blue and orange, respectively; Right panel: data points within the 2825477 to 2839408 bp O-antigen region are highlighted in orange. 

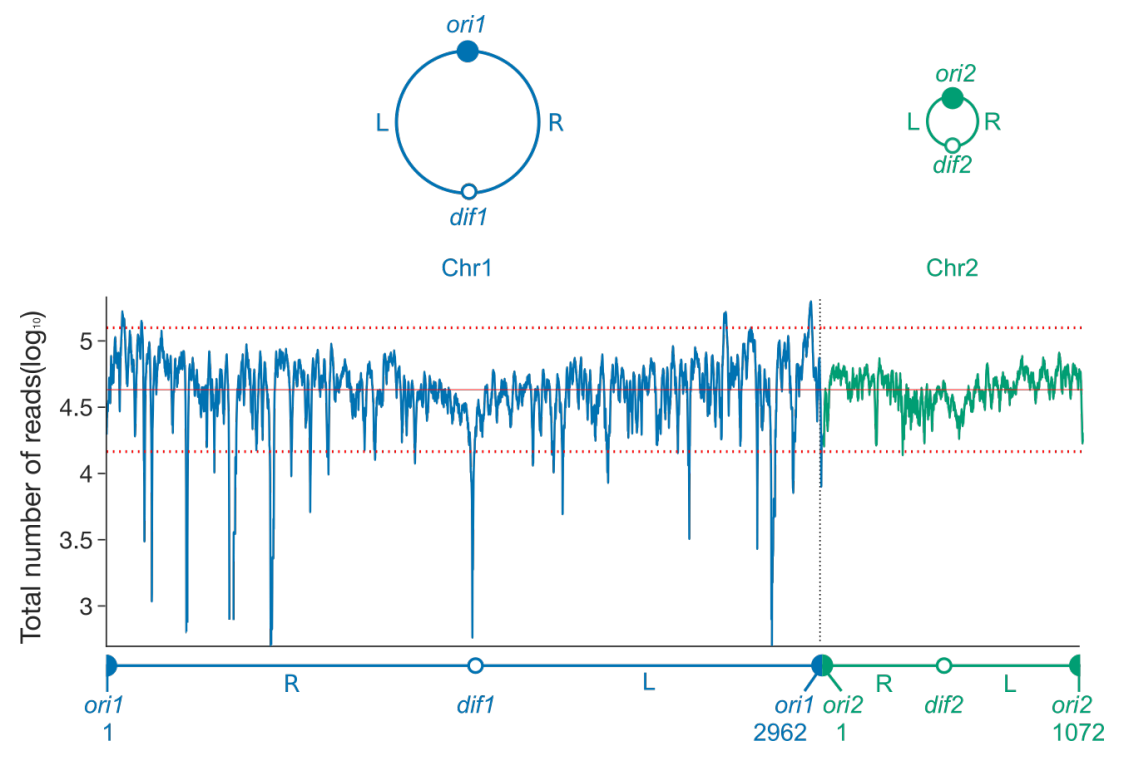

Figure S1. Typical SC2 reporter coverage map. The figure shows the total number of reads of the SC2 reporter in a $10 \mathrm{kbp}$ region surrounding each genomic position at the 90 ' time point of the experiment presented in Figure 1B (FX224 dataset). Read numbers are shown in log scale. The few positions where the number of reads was reduced correspond for the most part to repeated sequences, such as the ribosomal genes, which cannot be mapped. Note that $>500$ reads were obtained in the $10 \mathrm{kbp}$ surrounding almost all genomic positions, which is sufficient to estimate $f_{S C 2}$ at this resolution. Chr1 and Chr2 schematic maps and Chr1 and Chr2 insertion data profiles are shown in blue and green, respectively. The length of the chromosomes is indicated in kbp on the linear map. The chromosome coordinates are set so that the region of the origin of replication of each chromosome is at the start and end of the linear map representation (filled circles). The region of their terminus of replication region is located in the middle of the linear map (open circles). Plain and doted horizontal lines show the position of the mean (4.64) \pm twice the standard deviation (0.23) of the data. 

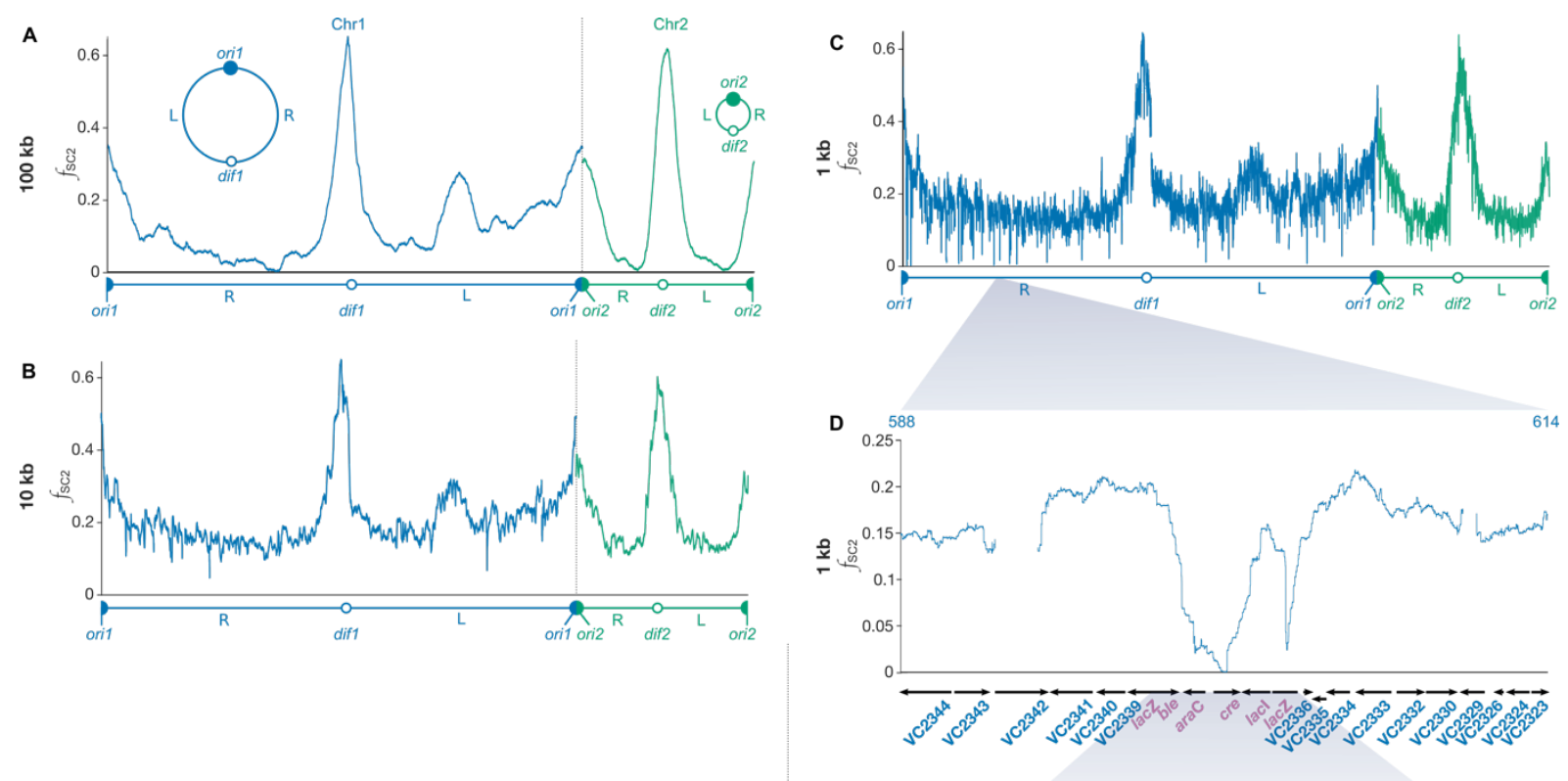

E

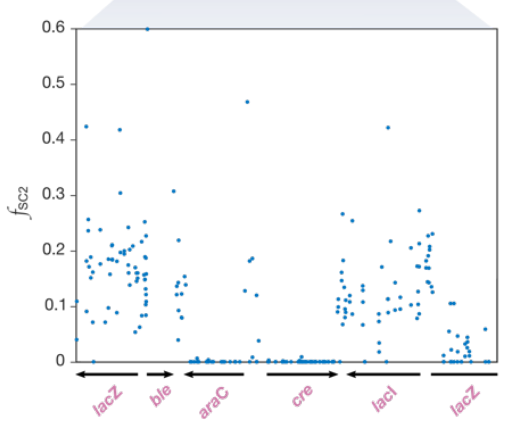

Figure S2. Short-range and large-range variations in sister chromatid cohesion. Hi-SC2 data can be represented using $100 \mathrm{kbp}(\mathrm{A}), 10 \mathrm{kbp}(\mathrm{B})$ or $1 \mathrm{kbp}(\mathrm{C})$ sliding-windows to highlight large-range and short-range variations in the relative frequency of sister chromatid contacts. The data corresponds to the 90' time point of the Cre-based assay shown in Figure 1 (FX224 dataset). (D) Zoom of the $1 \mathrm{kbp}$ excision profile around the region of insertion of Cre (from position 588 to $615 \mathrm{kbp}$ ). (E) Zoom on the frequency of excision around the region of insertion of Cre (from position 598254 to 604418 bp), showing the frequency of excision at each position of insertion of the SC2 reporter. As expected, no excision is observed for reporters inserted in the cre and $\operatorname{araC}$ genes. 
A

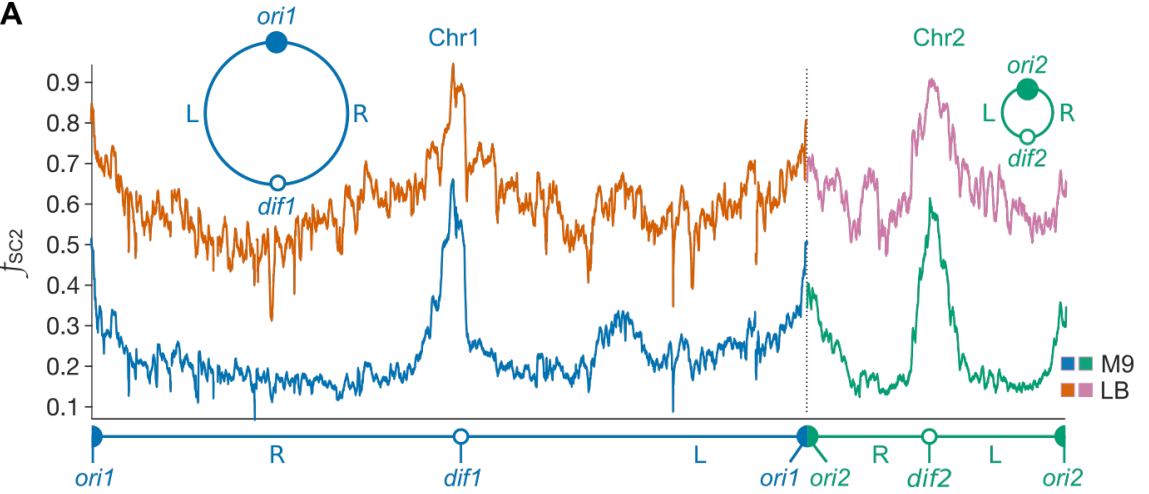

B

Chr1

Chr2
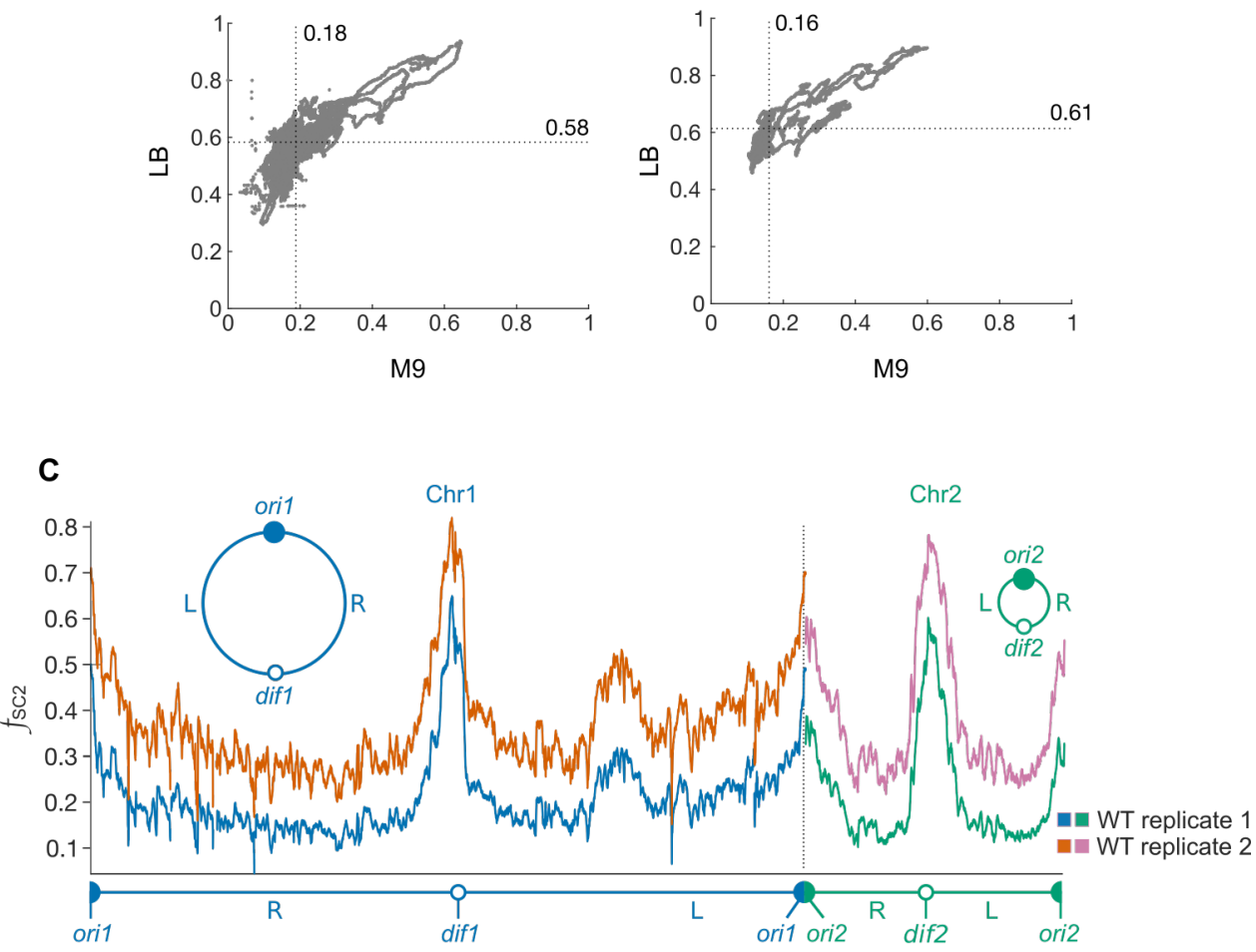

D

Chr1

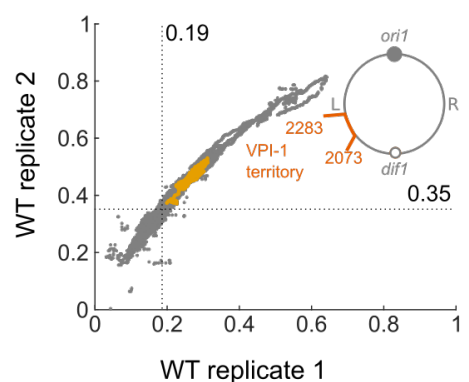

Chr2

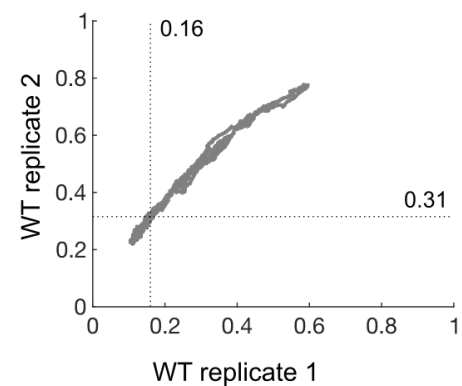


Figure S3. Validity of Hi-SC2 analysis. (A) Comparison of Cre-based $f_{S C 2}$ in cells under slow growth conditions (M9) and cells under fast growth conditions (LB). The data of the slow growth conditions corresponds to the 90' time point of Figure 1 (FX224 dataset, blue and green lines). The data of the fast growth conditions was obtained after 60' of induction of Cre (FX129 dataset, orange and pink lines). Despite the shorter induction time, fast-growth $f_{S C 2}$ was higher than slow-growth $f_{S C 2}$ at all genomic positions, as expected from the increase in the number of replication cycles. The difference in the Hi-SC2 profiles under slow- and fast-growth is particularly evident in the middle of the replication arms of the two chromosomes. (B) Crebased $f_{S C 2}$ under fast growth versus Cre-based $f_{S C 2}$ under slow growth. The horizontal and vertical dotted lines indicate the position of the median $f_{S C 2}$ in the FX129 and FX224 dataset, respectively. (C) Reproducibility of Hi-SC2. Blue and green lines: Hi-SC2 profile obtained under slow growth condition after 90' of Cre-induction shown in Figure 1 (FX224 dataset); Orange and pink lines: Hi-SC2 profile obtained for a second transposition library under the same experimental conditions (FX239 dataset). The $f_{S C 2}$ of the FX239 dataset were slightly higher than those of the FX224 dataset, which probably reflects a difference of growth between the two experiments. Note, however, that long-distance variations and short-distance fluctuations were almost identical. (D) Cre-based $f_{S C 2}$ from the FX239 dataset vs Cre-based $f_{S C 2}$ from the FX224 dataset. The horizontal and vertical dotted lines indicate the position of the median $f_{S C 2}$ in the FX239 dataset and the FX224 dataset, respectively. The positions corresponding to the VPI-1 territory are highlighted in orange (from position 2176653 to position 2217966). 


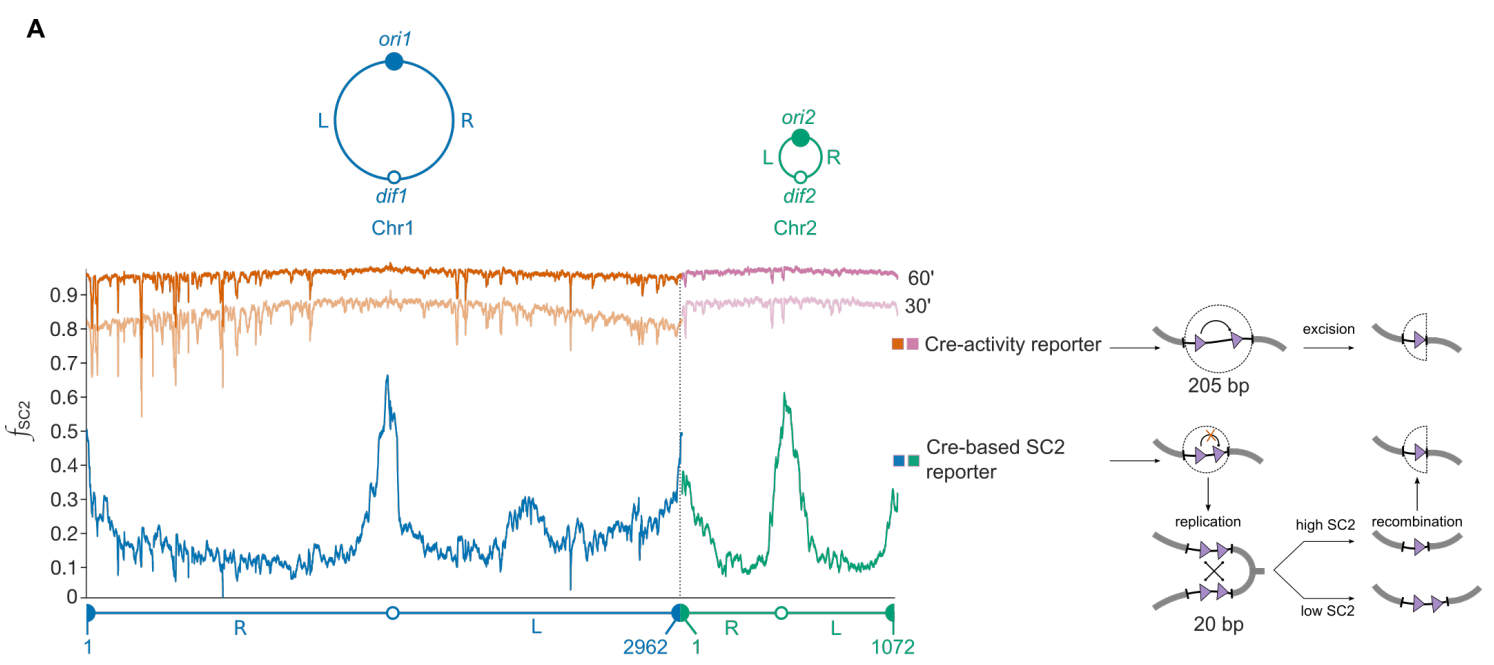

B
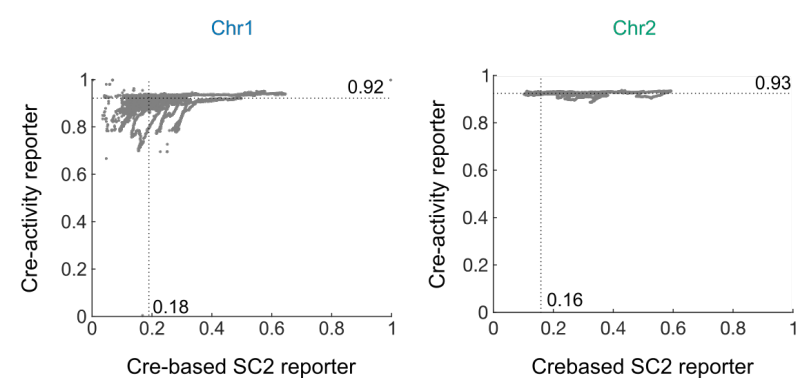

Figure S4. Accessibility of genomic positions to Cre and activity of Cre along the genome.

(A) Cre-activity reporter cassette excision frequency profiles obtained under slow growth conditions after 30' and 60' of induction of Cre (FX226 and FX227 dataset, respectively) and Cre-based Hi-SC2 profile of the 90' time point of Figure 1 (FX224 dataset). A schematic representation of the site-specific recombination cassette for the Cre-activity reporter and Crebased SC2 reporter is drawn in the left part of the panel. The excision of the Cre-activity reporter cassette reached an average of $80 \%$ after only 30 '. This is much more than $\boldsymbol{f}_{\boldsymbol{S C 2}}$ at all genomic positions after 30', 60' and 90' of Cre production (Figure 1), in agreement with the hypothesis that replacement of one of the two SC2 reporter copies by a single SSR site mainly resulted from intermolecular recombination events. With the exception of a few loci, excision of the long cassette was constant along the genome, further indicating that Cre had a similar access to most chromosomal regions and was active at most positions. (B) Excision frequencies of the 
FX227 dataset versus the $\boldsymbol{f}_{\boldsymbol{S C} 2}$ of the FX224 dataset. The horizontal and vertical dotted lines indicate the position of the median frequencies of excision frequencies in the FX227 data set and $\boldsymbol{f}_{\boldsymbol{S C 2}}$ in the FX224 dataset, respectively. Long-distance variations in the frequency of excision of the SC2-reporter cassettes do not correlate with Cre-based $\boldsymbol{f}_{\boldsymbol{S C 2}}$ variations. 
A
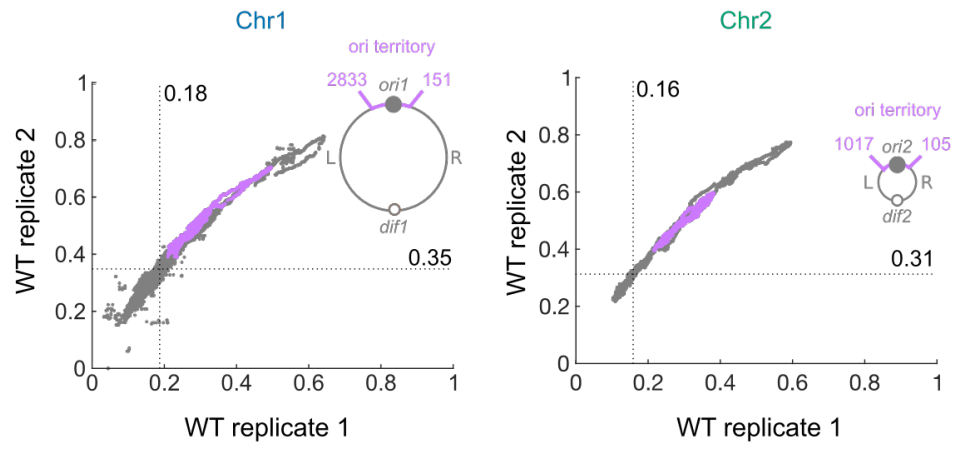

B
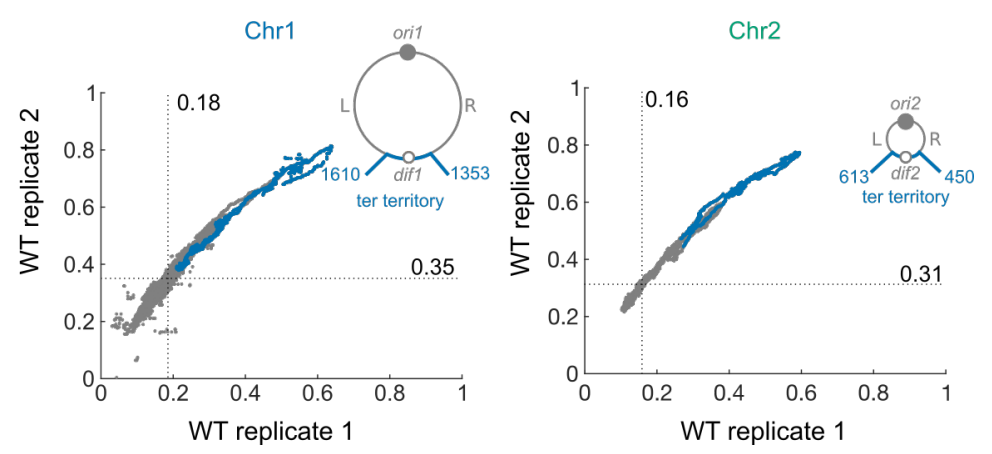

Figure S5. Large territories centred around the origin and terminus of replication of the

two $\boldsymbol{V}$. cholerae chromosomes are highly-cohesive. Cre-based $\boldsymbol{f}_{\boldsymbol{S C 2}}$ of the FX239 dataset vs Cre-based $\boldsymbol{f}_{\boldsymbol{S C 2}}$ of the FX224 dataset. The horizontal and vertical dotted lines indicate the position of the median $\boldsymbol{f}_{\boldsymbol{S C} 2}$ in the FX239 and FX224 dataset, respectively. Positions belonging to the oril and ori2 territories (A) and dif1 and dif2 domains territories (B) are highlighted in pink and blue, respectively. 


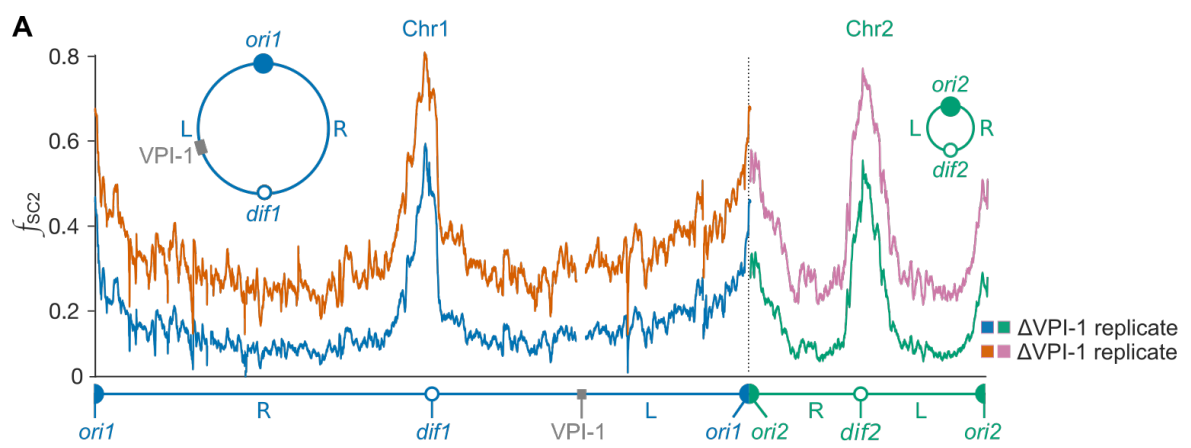

B
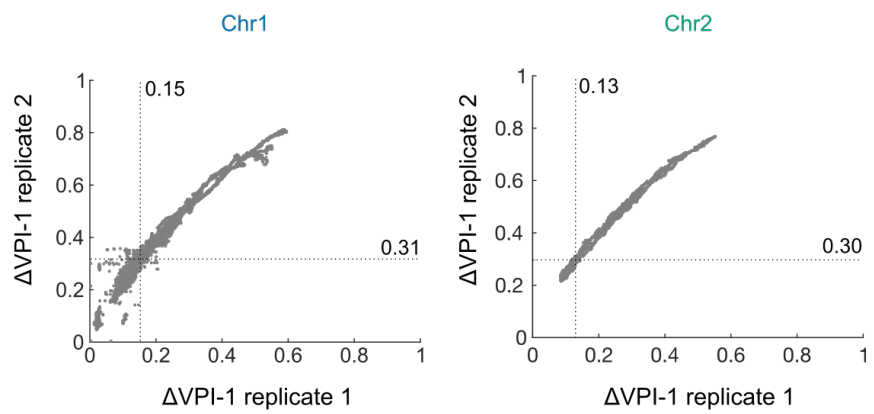

C

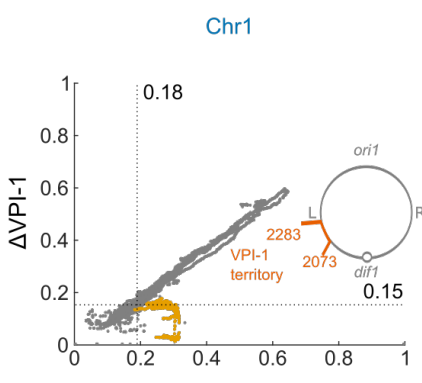

WT

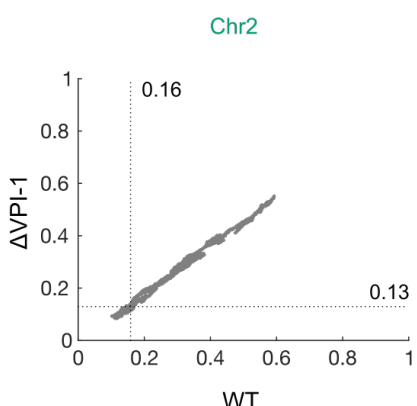

WT

Figure S6. VPI-1 is responsible for the high cohesiveness of the VPI-1 domain. (A)

Reproducibility of the Hi-SC2 profiles in $\triangle$ VPI-1 cells. Comparison of the 90' time point of the Cre-based Hi-SC2 profile of Figure 2A (FX230 dataset) and the results obtained with an independent $\Delta$ VPI-1 transposition library at the same time point (FX243 dataset). (B) Cre-based $\boldsymbol{f}_{\boldsymbol{S C 2}}$ from the FX230 dataset vs Cre-based $\boldsymbol{f}_{\boldsymbol{S C 2}}$ from the FX243 dataset. The dotted horizontal and vertical lines indicate the position of the median $\boldsymbol{f}_{\boldsymbol{S C 2}}$ in the FX243 and FX230 datasets, respectively. (C) Cre-based $\boldsymbol{f}_{\boldsymbol{S C 2}}$ in $\Delta$ VPI-1 cells (FX230 dataset) vs Cre-based $\boldsymbol{f}_{\boldsymbol{S C} 2}$ in wildtype cells (FX224 dataset). The dotted horizontal and vertical lines indicate the position of the 
median $\boldsymbol{f}_{\boldsymbol{S C 2}}$ in the FX230 and FX224 datasets, respectively. The VPI-1 territory is indicated in orange. Loss of SC2 in the VPI-1 territory when VPI-1 is deleted is highlighted in orange (from position 2176653 to position 2217966). 
A

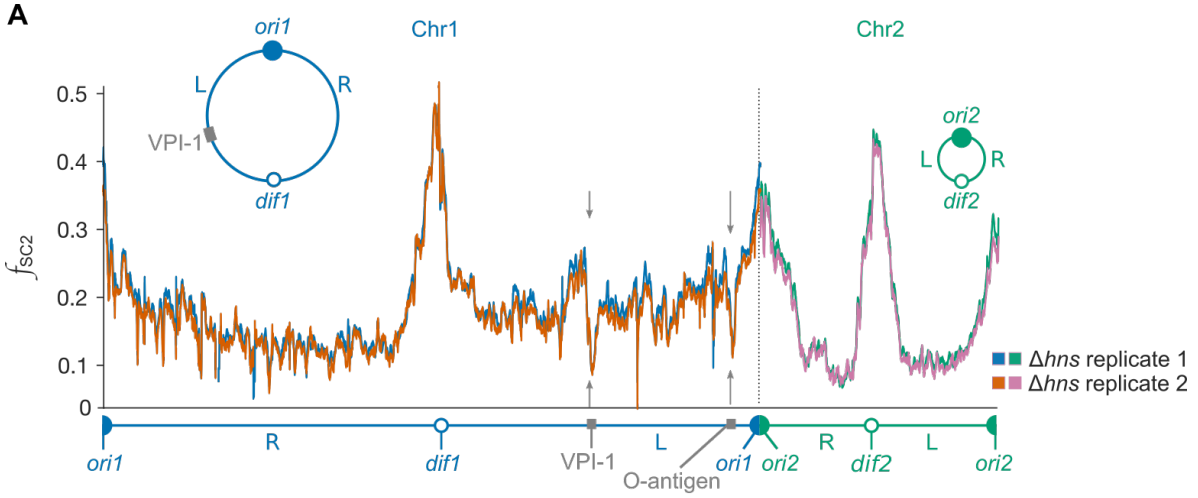

B
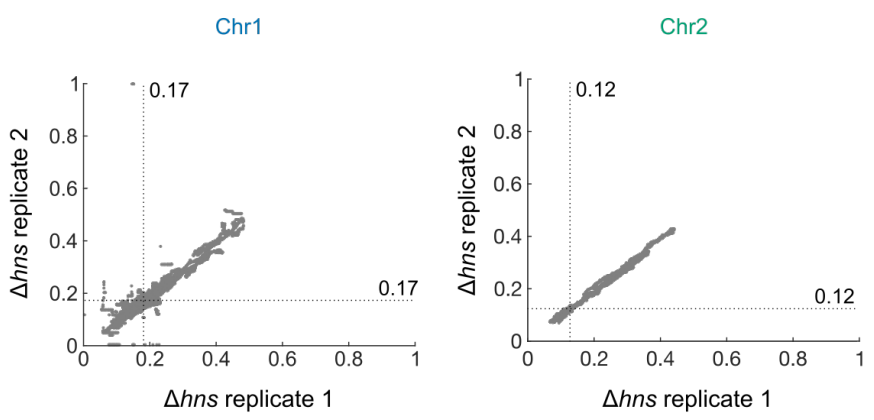

C
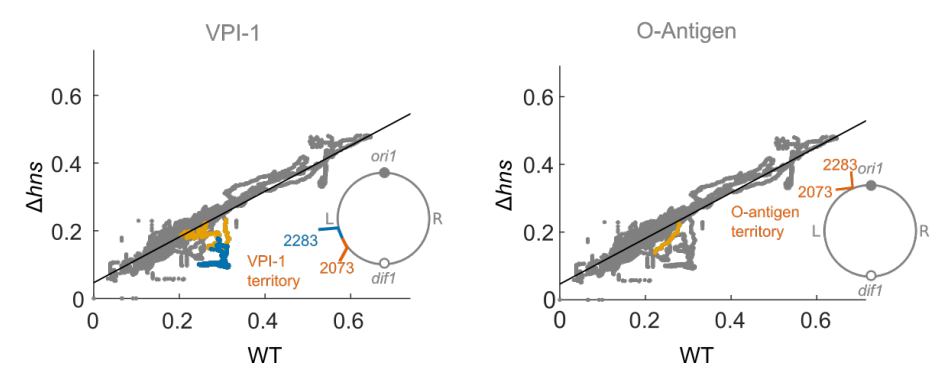

Figure S7. H-NS increases the cohesiveness of two regions implicated in $V$. cholerae virulence. (A) Reproducibility of the Hi-SC2 profiles in $\Delta h n s$ strains. Comparison of the 90' time point of the Cre-based Hi-SC2 profile of Figure 3A (FX215 dataset) and the results obtained with an independent cell library at the same time point (FX241 dataset). Grey arrows indicate regions of significantly lower SC2 frequencies in $\Delta h n s$ cells. (B) Cre-based $\boldsymbol{f}_{\boldsymbol{S C 2}}$ in the FX215 dataset vs Cre-based $\boldsymbol{f}_{\boldsymbol{S C} 2}$ in the FX241 dataset. The dotted horizontal and vertical lines indicate the position of the median $\boldsymbol{f}_{\boldsymbol{S C} 2}$ in the FX241 and FX215 datasets, respectively. (C) 
Cre-based $\boldsymbol{f}_{\boldsymbol{S C} \boldsymbol{2}}$ in $\Delta h n s$ cells (FX215 dataset) vs Cre-based $\boldsymbol{f}_{\boldsymbol{S C 2}}$ in wild-type cells (FX224 dataset). Black line: linear regression of the $\Delta h n s$ and WT data. Left panel: data points within VPI-1 and the 2160 to $2283 \mathrm{kbp}$ origin-proximal part of the VPI-1 territory are highlighted in blue and orange, respectively; Right panel: data points within the 2825477 to 2839408 bp Oantigen region are highlighted in orange. 
Table S1. List of Hi-SC2 experiments.

\begin{tabular}{|c|c|c|c|c|c|c|c|c|}
\hline Strain & Reporter & $\begin{array}{l}\text { Clone } \\
\text { number }\end{array}$ & Media & $\begin{array}{l}\text { Cre } \\
\text { induction } \\
\text { time } \\
(\mathrm{min})\end{array}$ & Dataset & $\begin{array}{l}\text { Read } \\
\text { number }\end{array}$ & $\begin{array}{l}\text { Valid } \\
\text { number of } \\
\text { reads }\end{array}$ & $\begin{array}{l}\text { Mapped } \\
\text { insertions }\end{array}$ \\
\hline \multirow{13}{*}{ EEV29 } & \multirow{2}{*}{$\begin{array}{l}\text { Xer- } \\
\text { based } \\
\text { SC2 } \\
\text { reporter }\end{array}$} & \multirow{2}{*}{347,000} & \multirow{2}{*}{ M9 } & $\mathrm{NI}$ & FX202 & $18,018,685$ & $17,007,277$ & $14,997,563$ \\
\hline & & & & 300 & FX205 & $17,066,405$ & $16,494,988$ & $14,637,494$ \\
\hline & \multirow{4}{*}{$\begin{array}{l}\text { Cre- } \\
\text { based } \\
\text { SC2 } \\
\text { reporter }\end{array}$} & \multirow{4}{*}{467,000} & \multirow{4}{*}{ M9 } & $\mathrm{NI}$ & FX221 & $23,837,826$ & $23,087,018$ & $15,483,425$ \\
\hline & & & & 30 & FX222 & $27,374,911$ & $26,589,027$ & $19,411,784$ \\
\hline & & & & 60 & FX223 & $12,557,780$ & $11,714,405$ & $8,951,733$ \\
\hline & & & & 90 & FX224 & $26,430,938$ & $25,864,693$ & $20,245,240$ \\
\hline & \multirow{2}{*}{$\begin{array}{l}\text { Cre- } \\
\text { based } \\
\text { SC2 } \\
\text { reporter }\end{array}$} & \multirow{2}{*}{400,000} & \multirow{2}{*}{ M9 } & $\mathrm{NI}$ & FX238 & $12,376,913$ & $11,646,264$ & $10,058,544$ \\
\hline & & & & 90 & FX239 & $15,941,629$ & $15,500,388$ & $13,497,374$ \\
\hline & \multirow{3}{*}{$\begin{array}{l}\text { Cre- } \\
\text { activity } \\
\text { reporter }\end{array}$} & \multirow{3}{*}{569,000} & \multirow{3}{*}{ M9 } & $\mathrm{NI}$ & FX225 & $14,627,990$ & $14,308,341$ & $10,540,592$ \\
\hline & & & & 30 & FX226 & $28,270,676$ & $27,679,114$ & $22,665,278$ \\
\hline & & & & 60 & FX227 & $26,683,039$ & $25,608,567$ & $21,300,506$ \\
\hline & \multirow{2}{*}{$\begin{array}{l}\text { Cre- } \\
\text { based } \\
\text { SC2 } \\
\text { reporter }\end{array}$} & \multirow{2}{*}{386,000} & \multirow{2}{*}{ LB } & $\mathrm{NI}$ & FX126 & $11,593,777$ & $11,393,652$ & $10,287,107$ \\
\hline & & & & 60 & FX129 & $11,420,532$ & $11,127,758$ & $9,990,084$ \\
\hline \multirow{2}{*}{ EEV111 } & \multirow{2}{*}{$\begin{array}{l}\text { Cre- } \\
\text { based } \\
\text { SC2 } \\
\text { reporter }\end{array}$} & \multirow{2}{*}{431,000} & \multirow{2}{*}{ M9 } & $\mathrm{NI}$ & FX229 & $26,947,308$ & 26220063 & $10,713,596$ \\
\hline & & & & 90 & FX230 & $42,261,001$ & $41,160,071$ & $22,040,745$ \\
\hline \multirow{2}{*}{ EEV112 } & \multirow{2}{*}{$\begin{array}{l}\text { Cre- } \\
\text { based } \\
\text { SC2 } \\
\text { reporter }\end{array}$} & \multirow{2}{*}{476,000} & \multirow{2}{*}{ M9 } & $\mathrm{NI}$ & FX242 & $14,106,539$ & $13,763,589$ & $11,036,874$ \\
\hline & & & & 90 & FX243 & $20,020,203$ & $19,444,546$ & $16,501,217$ \\
\hline \multirow{2}{*}{ EEV113 } & \multirow{2}{*}{$\begin{array}{l}\text { Cre- } \\
\text { based } \\
\text { SC2 } \\
\text { reporter }\end{array}$} & \multirow{2}{*}{607,000} & \multirow{2}{*}{ M9 } & $\mathrm{NI}$ & FX214 & $31,709,306$ & $30,847,276$ & $27,607,681$ \\
\hline & & & & 90 & FX215 & $34,713,327$ & $33,885,412$ & $30,922,757$ \\
\hline \multirow{2}{*}{ EEV114 } & \multirow{2}{*}{$\begin{array}{l}\text { Cre- } \\
\text { based } \\
\text { SC2 } \\
\text { reporter }\end{array}$} & \multirow{2}{*}{431,000} & \multirow{2}{*}{ M9 } & $\mathrm{NI}$ & FX240 & $20,439,647$ & $19,598,167$ & $18,179,412$ \\
\hline & & & & 90 & FX241 & $16,383,337$ & $15,965,291$ & $14,795,788$ \\
\hline
\end{tabular}

NI: Not induced. The Hi-SC2 Sequence data was deposited in the ArrayExpress Archive of Functional Genomics Data (https://www.ebi.ac.uk/arrayexpress/). 
Table S2. Strains used in the study.

\begin{tabular}{|c|c|c|}
\hline Strain & Genotype/Description & Reference \\
\hline EEV29 & $\begin{array}{l}\text { N16961 ChapR } \Delta / a c Z P_{B A D}-C r e-i n v P_{l a c}:: F R T-b l e-F R T, \\
Z^{2} o^{R}, G^{R}\end{array}$ & This study \\
\hline EEV111 & EEV29 $\Delta$ VPI-1::bla, Amp ${ }^{R}, \mathrm{Zeo}^{R}, \mathrm{Gm}^{\mathrm{R}}$ & This study \\
\hline EEV112 & EEV29 $\Delta$ VPI-1::bla, Amp ${ }^{R}, Z^{2} o^{R}, \mathrm{Gm}^{R}$ & This study \\
\hline EEV113 & EEV29 $\Delta h n s::$ bla, $\mathrm{Amp}^{\mathrm{R}}, \mathrm{Zeo}^{\mathrm{R}}, \mathrm{Gm}^{\mathrm{R}}$ & This study \\
\hline EEV114 & EEV29 $\Delta$ hns:: bla, $\mathrm{Amp}^{\mathrm{R}}, \mathrm{Zeo}^{\mathrm{R}}, \mathrm{Gm}^{\mathrm{R}}$ & This study \\
\hline EEV136 & $\begin{array}{l}\text { N16961 ChapR } \triangle \text { lacZ Plac-lacl-RFP-parBPMT1-YGFP + } \\
\text { LacOarray-aph on chromosome } 1 \text { at position } 2.043 \mathrm{Mb}+ \\
\text { tet'-parSPMT1-cat-'tet inserted on chromosome } 1 \text { at } \\
\text { position } 2.12 \mathrm{MB}, \mathrm{Kan}^{\mathrm{R}}, \mathrm{Cm}^{\mathrm{R}}, \mathrm{Gm}^{\mathrm{R}}\end{array}$ & This study \\
\hline EEV139 & 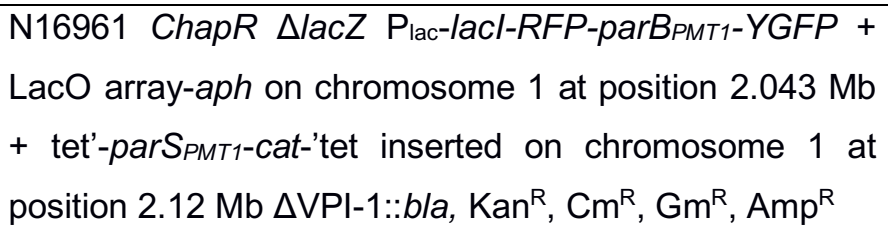 & This study \\
\hline EEV172 & $\begin{array}{l}\text { N16961 ChapR } \triangle \text { lacZ Plac-lacl-RFP-parB }{ }_{P M T 1} \text {-YGFP + } \\
\text { LacO array-aph on chromosome } 1 \text { at position } 0.85 \mathrm{Mb}+ \\
\text { tet'-parSPMT1-cat-'tet inserted on chromosome } 1 \text { at } \\
\text { position } 0.814 \mathrm{MB}, \mathrm{Kan}^{\mathrm{R}}, \mathrm{Cm}^{\mathrm{R}}, \mathrm{Gm}^{\mathrm{R}}\end{array}$ & This study \\
\hline GDV28 & $\begin{array}{l}\text { N16961 ChapR } \Delta \text { lacZ PBAD-xerC-invPlac-aadA1 } \text { Spec }^{R} \text {, } \\
\text { Gm }^{R}\end{array}$ & (Demarre et al., 2014) \\
\hline $\mathrm{DH} 5 \alpha$ & DH5a $\lambda$ pir & Lab stock \\
\hline$\beta 2163$ & (F-) RP4-2-Tc::Mu DAP- Kan ${ }^{R}$ & (Demarre et al., 2005) \\
\hline FCV14 & DH5a $\lambda$ pir $\Delta x e r C$ & Lab stock \\
\hline EE6 & $\beta 2163 \Delta x e r C$ Kan $^{R}$ Spec $^{R}$ & This study \\
\hline EE13 & EE6/ pEE20 & This study \\
\hline EE14 & $\beta 2163 / p E E 22$ & This study \\
\hline EE15 & $\beta 2163 / p E E 56$ & This study \\
\hline
\end{tabular}

Zeo: Zeocin; Gm: Gentamicin; Amp: Ampicilin; Kan: Kanamycin; Spec: Spectinomycin; Cm: Chloramphenicol 
Table S3. Plasmids used in the study.

\begin{tabular}{|c|c|c|c|}
\hline Plasmid & $\begin{array}{l}\text { Derived } \\
\text { from }\end{array}$ & Description & Reference \\
\hline pEE20 & pSW23T & $\begin{array}{l}\text { Ori R6K Cm }{ }^{R} \text { magellan5-Mmel }\left(\mathrm{Kan}^{\mathrm{R}}\right) . \mathrm{Rd} 2 \mathrm{SP} \text { sequence. } \\
\text { Xer-based SC2 reporter ( } 27 \text { bp between dif1 sites). }\end{array}$ & This study \\
\hline pEE22 & pSW23T & $\begin{array}{l}\text { Ori R6K } \mathrm{Cm}^{\mathrm{R}} \text { magellan5-Mmel }\left(\mathrm{Kan}^{\mathrm{R}}\right) . \mathrm{Rd} 2 \mathrm{SP} \text { sequence. } \\
\text { Cre-based SC2 reporter ( } 20 \text { bp between loxP sites). }\end{array}$ & This study \\
\hline pEE23 & pUC18 & $\begin{array}{l}\text { Plasmid for natural transformation carrying } \mathrm{P}_{\mathrm{BAD}} \text {-Cre- } \\
\text { invPlac::FRT-ble-FRT between two homologous regions of } \\
\text { V. cholerae lacZ, Amp }{ }^{R}, \mathrm{ZeO}^{R}\end{array}$ & This study \\
\hline pEE44 & pUC18 & $\begin{array}{l}\text { Plasmid for natural transformation carrying FRT-bla-FRT } \\
\text { between homologous regions of } V \text {. cholerae upstream and } \\
\text { downstream of VPI- } 1 \mathrm{Cm}^{R}, \mathrm{Amp}^{\mathrm{R}}\end{array}$ & This study \\
\hline pEE46 & pUC18 & $\begin{array}{l}\text { Plasmid for natural transformation carrying FRT-bla-FRT } \\
\text { between homologous regions of } V \text {. cholerae upstream and } \\
\text { downstream of } h n s \mathrm{Cm}^{\mathrm{R}}, \mathrm{Amp}^{\mathrm{R}}\end{array}$ & This study \\
\hline pEE56 & pSW23T & $\begin{array}{l}\text { Ori R6K Cm }{ }^{R} \text { magellan5-Mmel }\left(\mathrm{Kan}^{\mathrm{R}}\right) . \mathrm{Rd} 2 \mathrm{SP} \text { sequence. } \\
\text { Cre-activity reporter ( } 205 \mathrm{bp} \text { between loxP sites). }\end{array}$ & This study \\
\hline pSW23T & - & 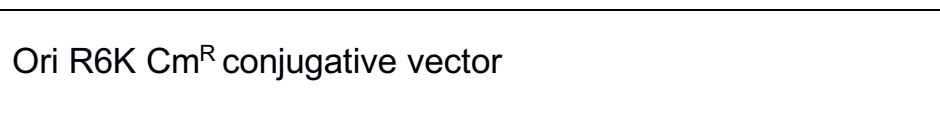 & $\begin{array}{l}\text { (Demarre et al., } \\
2014)\end{array}$ \\
\hline
\end{tabular}


Table S4. Oligonucleotides.

\begin{tabular}{|c|c|}
\hline Oligo & Sequence 5'-3' \\
\hline & Adapters \\
\hline 3455 & TTCCCTACACGACGCTCTTCCGATCTCAGTNN \\
\hline 3456 & ACTGAGATCGGAAGAGCGTCGTGTAGGG \\
\hline 3811 & TTCCCTACACGACGCTCTTCCGATCTCGTANN \\
\hline 3812 & TACGAGATCGGAAGAGCGTCGTGTAGGG \\
\hline 3813 & TTCCCTACACGACGCTCTTCCGATCTACAGTNN \\
\hline 3814 & ACTGTAGATCGGAAGAGCGTCGTGTAGGG \\
\hline 3815 & TTCCCTACACGACGCTCTTCCGATCTTACTCNN \\
\hline 3816 & GAGTAAGATCGGAAGAGCGTCGTGTAGGG \\
\hline 3817 & TTCCCTACACGACGCTCTTCCGATCTCTAGTNN \\
\hline 3818 & ACTAGAGATCGGAAGAGCGTCGTGTAGGG \\
\hline 3819 & TTCCCTACACGACGCTCTTCCGATCTTGACTCNN \\
\hline 3820 & GAGTCAAGATCGGAAGAGCGTCGTGTAGGG \\
\hline 3821 & TTCCCTACACGACGCTCTTCCGATCTATGCTANN \\
\hline 3822 & TAGCATAGATCGGAAGAGCGTCGTGTAGGG \\
\hline 3823 & TTCCCTACACGACGCTCTTCCGATCTAGCATANN \\
\hline \multirow[t]{2}{*}{3824} & TATGCTAGATCGGAAGAGCGTCGTGTAGGG \\
\hline & ILLUMINA OLIGOS (P5) \\
\hline 3457 & AATGATACGGCGACCACCGAGATCTACACTCTTTCCCTACACGACGCTCTTCCGATCTCAGT \\
\hline 3825 & AATGATACGGCGACCACCGAGATCTACACTCTTTCCCTACACGACGCTCTTCCGATCTCGTA \\
\hline 3826 & AATGATACGGCGACCACCGAGATCTACACTCTTTCCCTACACGACGCTCTTCCGATCTACAGT \\
\hline 3827 & AATGATACGGCGACCACCGAGATCTACACTCTTTCCCTACACGACGCTCTTCCGATCTTACTC \\
\hline 3828 & AATGATACGGCGACCACCGAGATCTACACTCTTTCCCTACACGACGCTCTTCCGATCTCTAGT \\
\hline 3829 & AATGATACGGCGACCACCGAGATCTACACTCTTTCCCTACACGACGCTCTTCCGATCTTGACTC \\
\hline 3830 & AATGATACGGCGACCACCGAGATCTACACTCTTTCCCTACACGACGCTCTTCCGATCTATGCTA \\
\hline \multirow[t]{2}{*}{3831} & AATGATACGGCGACCACCGAGATCTACACTCTTTCCCTACACGACGCTCTTCCGATCTAGCATA \\
\hline & ILLUMINA OLIGOS (P7) \\
\hline 3539 & CAAGCAGAAGACGGCATACGAGATGTCGTCGTGACTGGAGTTCAGACGTGTGCTCTTCCGATCTTCTA \\
\hline 3540 & CAAGCAGAAGACGGCATACGAGATTGCCGAGTGACTGGAGTTCAGACGTGTGCTCTTCCGATCTTCTA \\
\hline 3608 & CAAGCAGAAGACGGCATACGAGATATCAGTGTGACTGGAGTTCAGACGTGTGCTCTTCCGATCTTCTA \\
\hline 3609 & CAAGCAGAAGACGGCATACGAGATGCTCATGTGACTGGAGTTCAGACGTGTGCTCTTCCGATCTTCTA \\
\hline 3654 & CAAGCAGAAGACGGCATACGAGATCGTGATGTGACTGGAGTTCAGACGTGTGCTCTTCCGATCTTCTA \\
\hline 3655 & CAAGCAGAAGACGGCATACGAGATCACTGTGTGACTGGAGTTCAGACGTGTGCTCTTCCGATCTTCTA \\
\hline 3656 & CAAGCAGAAGACGGCATACGAGATCTGATCGTGACTGGAGTTCAGACGTGTGCTCTTCCGATCTTCTA \\
\hline 3657 & CAAGCAGAAGACGGCATACGAGATTGACATGTGACTGGAGTTCAGACGTGTGCTCTTCCGATCTTCTA \\
\hline 3658 & CAAGCAGAAGACGGCATACGAGATCTCTACGTGACTGGAGTTCAGACGTGTGCTCTTCCGATCTTCTA \\
\hline 3659 & CAAGCAGAAGACGGCATACGAGATGTAGCCGTGACTGGAGTTCAGACGTGTGCTCTTCCGATCTTCTA \\
\hline
\end{tabular}


Table S5. Essential genes and intergenic regions. EA: EL-ARTIST; 2: locus essential for optimal growth; 3: locus domain essential; IG: Intergenic region.

\begin{tabular}{|c|c|}
\hline Locus & EA \\
\hline IG_VC001 & 2 \\
\hline vc0001 & 3 \\
\hline Vc0002 & 2 \\
\hline Vc0003 & 3 \\
\hline VC0004 & 2 \\
\hline VC0005 & 3 \\
\hline vc0006 & 2 \\
\hline VC0007 & 2 \\
\hline IG_VC0008 & 3 \\
\hline IG_VC0012 & 2 \\
\hline Vc0012 & 2 \\
\hline IG_VC0013 & 2 \\
\hline vc0013 & 2 \\
\hline vc0015 & 2 \\
\hline vc0020 & 2 \\
\hline vc0021 & 2 \\
\hline VC0024 & 2 \\
\hline VC0028 & 2 \\
\hline vc0029 & 3 \\
\hline VC0043 & 2 \\
\hline VC0045 & 2 \\
\hline VC0055 & 2 \\
\hline IG_VC0056 & 2 \\
\hline vc0056 & 3 \\
\hline Vc0083 & 2 \\
\hline VC0084 & 2 \\
\hline VC0085 & 2 \\
\hline vc0094 & 2 \\
\hline VC0104 & 3 \\
\hline VC0105 & 2 \\
\hline VC0107 & 2 \\
\hline VC0108 & 3 \\
\hline VC0111 & 2 \\
\hline IG_VC0112 & 2 \\
\hline VC0119 & 2 \\
\hline VC0120 & 2 \\
\hline VC0122 & 3 \\
\hline VC0125 & 2 \\
\hline
\end{tabular}

\begin{tabular}{|c|c|}
\hline VC0126 & 2 \\
\hline IG_VC0143 & 3 \\
\hline VC0143 & 2 \\
\hline IG_VC0144 & 3 \\
\hline VC0147 & 2 \\
\hline VC0150 & 2 \\
\hline IG_VC0158 & 2 \\
\hline VC0158 & 2 \\
\hline VC2746 & 2 \\
\hline VC2734 & 3 \\
\hline IG_VC2732 & 2 \\
\hline VC2732 & 2 \\
\hline VC2731 & 2 \\
\hline VC2730 & 2 \\
\hline IG_VC2729 & 2 \\
\hline VC2729 & 2 \\
\hline VC2728 & 3 \\
\hline VC2727 & 2 \\
\hline VC2726 & 2 \\
\hline VC2725 & 2 \\
\hline VC2724 & 2 \\
\hline VC2720 & 3 \\
\hline VC2710 & 3 \\
\hline IG_VC2709 & 2 \\
\hline VC2709 & 3 \\
\hline VC2708 & 2 \\
\hline VC2689 & 2 \\
\hline VC2685 & 2 \\
\hline IG_VC2684 & 3 \\
\hline VC2679 & 3 \\
\hline IG_VC2678 & 2 \\
\hline VC2678 & 2 \\
\hline VC2676 & 2 \\
\hline IG_VC2675 & 3 \\
\hline VC2670 & 2 \\
\hline VC2665 & 2 \\
\hline IG_VC2664 & 2 \\
\hline VC2664 & 2 \\
\hline VC2661 & 2 \\
\hline
\end{tabular}

\begin{tabular}{|c|c|}
\hline IG_VC2660 & 2 \\
\hline VC2660 & 2 \\
\hline VC2655 & 3 \\
\hline VC2651 & 2 \\
\hline VC2650 & 2 \\
\hline VC2649 & 2 \\
\hline IG_VC2646 & 3 \\
\hline VC2645 & 2 \\
\hline IG_VC2644 & 2 \\
\hline VC2644 & 2 \\
\hline VC2643 & 2 \\
\hline IG_VC2642 & 2 \\
\hline VC2642 & 2 \\
\hline VC2641 & 2 \\
\hline VC2635 & 2 \\
\hline VC2629 & 2 \\
\hline VC2628 & 2 \\
\hline IG_VC2626 & 2 \\
\hline VC2626 & 2 \\
\hline VC2625 & 2 \\
\hline VC2624 & 3 \\
\hline VC2623 & 2 \\
\hline VC2618 & 3 \\
\hline IG_VC2617 & 2 \\
\hline VC2614 & 2 \\
\hline IG_VC2602 & 3 \\
\hline VC2602 & 2 \\
\hline IG_VC2601 & 3 \\
\hline IG_VC2597 & 3 \\
\hline VC2597 & 2 \\
\hline VC2596 & 2 \\
\hline IG_VC2595 & 2 \\
\hline VC2595 & 2 \\
\hline VC2594 & 2 \\
\hline VC2593 & 2 \\
\hline IG_VC2592 & 2 \\
\hline VC2592 & 2 \\
\hline IG_VC2591 & 2 \\
\hline VC2591 & 2 \\
\hline
\end{tabular}

\begin{tabular}{|c|c|}
\hline IG_VC2590 & 2 \\
\hline VC2590 & 2 \\
\hline VC2589 & 2 \\
\hline VC2588 & 2 \\
\hline VC2587 & 2 \\
\hline IG_VC2586 & 2 \\
\hline VC2586 & 2 \\
\hline VC2585 & 2 \\
\hline IG_VC2584 & 2 \\
\hline VC2584 & 2 \\
\hline IG_VC2583 & 2 \\
\hline VC2583 & 2 \\
\hline IG_VC2582 & 2 \\
\hline VC2582 & 2 \\
\hline IG_VC2581 & 2 \\
\hline VC2581 & 2 \\
\hline IG_VC2580 & 2 \\
\hline VC2580 & 2 \\
\hline VC2579 & 2 \\
\hline VC2578 & 2 \\
\hline VC2577 & 2 \\
\hline VC2576 & 2 \\
\hline IG_VC2575 & 2 \\
\hline VC2575 & 2 \\
\hline IG_VC2574 & 2 \\
\hline VC2574 & 2 \\
\hline IG_VC2573 & 2 \\
\hline VC2573 & 2 \\
\hline VC2572 & 2 \\
\hline IG_VC2571 & 2 \\
\hline VC2571 & 2 \\
\hline IG_VC2570 & 2 \\
\hline VC2570 & 2 \\
\hline IG_VC2569 & 3 \\
\hline VC2559 & 3 \\
\hline VC2558 & 3 \\
\hline VC2545 & 2 \\
\hline IG_VC2544 & 3 \\
\hline VC2541 & 2 \\
\hline
\end{tabular}

\begin{tabular}{|l|l|}
\hline VC2531 & 2 \\
\hline VC2528 & 2 \\
\hline VC2527 & 2 \\
\hline VC2525 & 2 \\
\hline VC2524 & 2 \\
\hline VC2523 & 2 \\
\hline VC2514 & 2 \\
\hline VC2513 & 2 \\
\hline VC2510 & 2 \\
\hline VC2509 & 2 \\
\hline VC2508 & 2 \\
\hline IG_VC2507 & 2 \\
\hline VC2503 & 2 \\
\hline IG_VC2500 & 3 \\
\hline VC2500 & 2 \\
\hline VC2499 & 2 \\
\hline VC2493 & 2 \\
\hline VC2492 & 2 \\
\hline IG_VC2491 & 2 \\
\hline VC2491 & 2 \\
\hline VC2490 & 3 \\
\hline IG_VC2486 & 3 \\
\hline VC2481 & 3 \\
\hline IG_VC2480 & 2 \\
\hline VC2480 & 2 \\
\hline IG_VC2479 & 3 \\
\hline VC2475 & 2 \\
\hline VC2474 & 2 \\
\hline VC2472 & 2 \\
\hline VC2467 & 2 \\
\hline VC2466 & 2 \\
\hline VC2465 & 2 \\
\hline VC2464 2462 & 2 \\
\hline IG_VC2461 & 2 \\
\hline VC2463 & 2 \\
\hline VC2 & 2 \\
\hline
\end{tabular}




\begin{tabular}{|c|c|}
\hline VC2460 & 2 \\
\hline VC2458 & 2 \\
\hline VC2457 & 2 \\
\hline VC2453 & 3 \\
\hline IG_VC2448 & 2 \\
\hline VC2448 & 2 \\
\hline IG_VC2447 & 2 \\
\hline VC2447 & 2 \\
\hline IG_VC2436 & 2 \\
\hline VC2433 & 2 \\
\hline VC2431 & 2 \\
\hline VC2430 & 2 \\
\hline VC2427 & 2 \\
\hline VC2426 & 2 \\
\hline IG_VC2414 & 2 \\
\hline VC2414 & 2 \\
\hline VC2413 & 2 \\
\hline IG_VC2412 & 3 \\
\hline VC2412 & 2 \\
\hline VC2410 & 2 \\
\hline IG_VC2409 & 3 \\
\hline VC2409 & 2 \\
\hline IG_VC2408 & 2 \\
\hline VC2408 & 2 \\
\hline VC2407 & 2 \\
\hline VC2406 & 2 \\
\hline VC2405 & 2 \\
\hline VC2404 & 2 \\
\hline VC2403 & 2 \\
\hline IG_VC2402 & 2 \\
\hline VC2402 & 2 \\
\hline VC2401 & 2 \\
\hline VC2400 & 2 \\
\hline IG_VC2399 & 3 \\
\hline VC2399 & 2 \\
\hline VC2398 & 2 \\
\hline VC2397 & 2 \\
\hline IG_VC2396 & 2 \\
\hline VC2396 & 2 \\
\hline IG_VC2395 & 2 \\
\hline VC2395 & 2 \\
\hline VC2394 & 2 \\
\hline
\end{tabular}

\begin{tabular}{|c|c|}
\hline VC2391 & 2 \\
\hline IG_VC2390 & 2 \\
\hline VC2390 & 2 \\
\hline IG_VC2389 & 2 \\
\hline VC2389 & 2 \\
\hline VC2387 & 2 \\
\hline IG_VC2386 & 2 \\
\hline VC2386 & 3 \\
\hline VC2385 & 2 \\
\hline VC2379 & 2 \\
\hline IG_VC2375 & 3 \\
\hline VC2375 & 3 \\
\hline VC2364 & 3 \\
\hline VC2363 & 2 \\
\hline VC2362 & 2 \\
\hline IG_VC2360 & 3 \\
\hline IG_VC2345 & 3 \\
\hline VC2345 & 2 \\
\hline IG_VC2342 & 3 \\
\hline VC2342 & 2 \\
\hline IG_Cre & 3 \\
\hline VC2329 & 2 \\
\hline VC2328 & 3 \\
\hline VC2322 & 2 \\
\hline VC2320 & 2 \\
\hline VC2316 & 2 \\
\hline IG_VC2315 & 3 \\
\hline VC2294 & 3 \\
\hline VC2293 & 2 \\
\hline VC2292 & 2 \\
\hline VC2291 & 2 \\
\hline IG_VC2290 & 2 \\
\hline VC2290 & 2 \\
\hline IG_VC2289 & 2 \\
\hline VC2289 & 2 \\
\hline VC2274 & 2 \\
\hline VC2273 & 2 \\
\hline VC2268 & 2 \\
\hline VC2267 & 2 \\
\hline VC2265 & 2 \\
\hline IG_VC2261 & 2 \\
\hline VC2261 & 2 \\
\hline
\end{tabular}

\begin{tabular}{|c|c|}
\hline IG_VC2260 & 2 \\
\hline VC2260 & 2 \\
\hline IG_VC2259 & 3 \\
\hline VC2259 & 2 \\
\hline IG_VC2258 & 3 \\
\hline VC2258 & 2 \\
\hline IG_VC2257 & 2 \\
\hline VC2257 & 2 \\
\hline IG_VC2256 & 2 \\
\hline VC2256 & 2 \\
\hline IG_VC2255 & 2 \\
\hline VC2255 & 2 \\
\hline IG_VC2254 & 2 \\
\hline VC2254 & 2 \\
\hline VC2253 & 2 \\
\hline IG_VC2252 & 2 \\
\hline VC2252 & 2 \\
\hline VC2250 & 2 \\
\hline IG_VC2249 & 2 \\
\hline VC2249 & 2 \\
\hline VC2248 & 2 \\
\hline IG_VC2247 & 2 \\
\hline VC2247 & 2 \\
\hline VC2245 & 2 \\
\hline VC2244 & 2 \\
\hline VC2243 & 2 \\
\hline VC2242 & 2 \\
\hline VC2234 & 2 \\
\hline IG_VC2233 & 2 \\
\hline VC2233 & 2 \\
\hline VC2230 & 2 \\
\hline IG_VC2229 & 3 \\
\hline IG_VC2218 & 2 \\
\hline VC2218 & 3 \\
\hline VC2214 & 2 \\
\hline VC2184 & 2 \\
\hline IG_VC2183 & 3 \\
\hline VC2183 & 2 \\
\hline VC2182 & 2 \\
\hline VC2181 & 2 \\
\hline VC2180 & 2 \\
\hline IG_VC2179 & 2 \\
\hline
\end{tabular}

\begin{tabular}{|c|c|}
\hline VC2179 & 2 \\
\hline VC2178 & 2 \\
\hline VC2175 & 2 \\
\hline IG_VC2157 & 3 \\
\hline VC2157 & 2 \\
\hline VC2152 & 2 \\
\hline VC2151 & 2 \\
\hline VC2116 & 2 \\
\hline IG_VC2115 & 3 \\
\hline VC2110 & 3 \\
\hline IG_VC2108 & 2 \\
\hline VC2108 & 2 \\
\hline VC2099 & 2 \\
\hline IG_VC2098 & 2 \\
\hline VC2096 & 2 \\
\hline VC2092 & 2 \\
\hline VC2089 & 3 \\
\hline VC2088 & 3 \\
\hline IG_VC2087 & 2 \\
\hline VC2087 & 2 \\
\hline IG_VC2086 & 2 \\
\hline VC2086 & 2 \\
\hline IG_VC2085 & 3 \\
\hline IG_VC2078 & 3 \\
\hline VC2074 & 2 \\
\hline VC2056 & 2 \\
\hline IG_VC2055 & 2 \\
\hline VC2045 & 2 \\
\hline VC2041 & 3 \\
\hline IG_VC2040 & 2 \\
\hline VC2040 & 2 \\
\hline VC2030 & 3 \\
\hline IG_VC2026 & 3 \\
\hline VC2026 & 2 \\
\hline IG_VC2025 & 2 \\
\hline VC2025 & 2 \\
\hline VC2024 & 2 \\
\hline VC2023 & 2 \\
\hline IG_VC2022 & 2 \\
\hline VC2022 & 2 \\
\hline VC2021 & 2 \\
\hline IG_VC2020 & 2 \\
\hline
\end{tabular}

\begin{tabular}{|c|c|}
\hline VC2020 & 2 \\
\hline VC2017 & 3 \\
\hline VC2016 & 2 \\
\hline VC2015 & 2 \\
\hline IG_VC2013 & 3 \\
\hline IG_VC2011 & 3 \\
\hline VC2000 & 2 \\
\hline IG_VC1999 & 3 \\
\hline VC1993 & 3 \\
\hline VC1989 & 2 \\
\hline VC1981 & 2 \\
\hline VC1948 & 3 \\
\hline VC1943 & 3 \\
\hline VC1942 & 2 \\
\hline IG_VC1941 & 3 \\
\hline VC1934 & 3 \\
\hline VC1922 & 2 \\
\hline VC1921 & 2 \\
\hline VC1916 & 2 \\
\hline IG_VC1915 & 2 \\
\hline VC1915 & 2 \\
\hline VC1914 & 2 \\
\hline IG_VC1913 & 2 \\
\hline VC1913 & 2 \\
\hline VC1912 & 2 \\
\hline IG_VC1911 & 2 \\
\hline VC1911 & 2 \\
\hline VC1907 & 2 \\
\hline IG_VC1906 & 3 \\
\hline IG_VC1904 & 3 \\
\hline VC1904 & 2 \\
\hline VC1903 & 2 \\
\hline VC1900 & 2 \\
\hline VC1895 & 3 \\
\hline IG_VC1894 & 2 \\
\hline VC1887 & 3 \\
\hline IG_VC1884 & 3 \\
\hline VC1884 & 2 \\
\hline VC1883 & 2 \\
\hline VC1882 & 2 \\
\hline VC1881 & 3 \\
\hline IG_VC1878 & 2 \\
\hline
\end{tabular}




\begin{tabular}{|c|c|}
\hline VC1878 & 2 \\
\hline VC1877 & 2 \\
\hline VC1876 & 2 \\
\hline VC1875 & 2 \\
\hline IG_VC1865 & 3 \\
\hline IG_VC1854 & 2 \\
\hline VC1850 & 2 \\
\hline IG_VC1849 & 2 \\
\hline VC1849 & 2 \\
\hline IG_VC1848 & 2 \\
\hline VC1848 & 2 \\
\hline VC1844 & 3 \\
\hline VC1843 & 3 \\
\hline VC1839 & 2 \\
\hline VC1838 & 2 \\
\hline VC1837 & 2 \\
\hline VC1836 & 2 \\
\hline IG_VC1835 & 2 \\
\hline VC1835 & 2 \\
\hline VC1826 & 3 \\
\hline IG_VC1825 & 2 \\
\hline VC1820 & 2 \\
\hline IG_VC1819 & 3 \\
\hline IG_VC1809 & 3 \\
\hline IG_VC1808 & 2 \\
\hline VC1808 & 2 \\
\hline IG_VC1806 & 3 \\
\hline VC1803 & 2 \\
\hline IG_VC1802 & 3 \\
\hline VC1800 & 3 \\
\hline IG_VC1739 & 3 \\
\hline VC1739 & 2 \\
\hline VC1738 & 2 \\
\hline VC1737 & 2 \\
\hline IG_VC1736 & 2 \\
\hline VC1733 & 3 \\
\hline VC1732 & 2 \\
\hline IG_VC1731 & 3 \\
\hline IG_VC1730 & 3 \\
\hline VC1730 & 2 \\
\hline VC1726 & 3 \\
\hline VC1706 & 2 \\
\hline
\end{tabular}

\begin{tabular}{|c|c|}
\hline IG_VC1704 & 3 \\
\hline VC1704 & 2 \\
\hline VC1684 & 3 \\
\hline VC1683 & 2 \\
\hline VC1682 & 2 \\
\hline VC1681 & 2 \\
\hline VC1680 & 2 \\
\hline IG_VC1679 & 3 \\
\hline VC1653 & 3 \\
\hline IG_VC1640 & 3 \\
\hline VC1640 & 2 \\
\hline IG_VC1639 & 2 \\
\hline VC1639 & 2 \\
\hline VC1617 & 3 \\
\hline VC1590 & 3 \\
\hline IG_VC1585 & 2 \\
\hline VC1573 & 3 \\
\hline VC1547 & 3 \\
\hline VC1546 & 3 \\
\hline IG_VC1539 & 3 \\
\hline IG_VC1495 & 2 \\
\hline IG_VC1491 & 3 \\
\hline VC1491 & 2 \\
\hline VC1489 & 3 \\
\hline IG_VC1488 & 3 \\
\hline VC1485 & 2 \\
\hline VC1483 & 2 \\
\hline IG_VC1482 & 2 \\
\hline VC1464 & 3 \\
\hline IG_VC1463 & 2 \\
\hline IG_VC1457 & 2 \\
\hline VC1456 & 3 \\
\hline VC1455 & 3 \\
\hline IG_VC1454 & 2 \\
\hline VC1449 & 3 \\
\hline IG_VC1448 & 2 \\
\hline VC1445 & 3 \\
\hline VC1437 & 3 \\
\hline VC1419 & 2 \\
\hline IG_VC1408 & 2 \\
\hline VC1408 & 3 \\
\hline VC1363 & 3 \\
\hline
\end{tabular}

\begin{tabular}{|c|c|}
\hline IG_VC1362 & 3 \\
\hline VC1358 & 3 \\
\hline VC1356 & 2 \\
\hline IG_VC1343 & 3 \\
\hline IG_VC1334 & 3 \\
\hline VC1330 & 3 \\
\hline IG_VC1301 & 3 \\
\hline VC1297 & 2 \\
\hline VC1293 & 3 \\
\hline IG_VC1278 & 3 \\
\hline IG_VC1263 & 3 \\
\hline VC1263 & 3 \\
\hline VC1258 & 2 \\
\hline IG_VC1257 & 3 \\
\hline VC1257 & 2 \\
\hline IG_VC1256 & 3 \\
\hline VC1256 & 2 \\
\hline IG_VC1255 & 2 \\
\hline VC1255 & 2 \\
\hline IG_VC1252 & 3 \\
\hline VC1246 & 2 \\
\hline IG_VC1245 & 3 \\
\hline VC1222 & 2 \\
\hline VC1221 & 2 \\
\hline IG_VC1220 & 2 \\
\hline VC1220 & 2 \\
\hline IG_VC1219 & 2 \\
\hline VC1219 & 2 \\
\hline VC1218 & 2 \\
\hline VC1215 & 2 \\
\hline VC1213 & 2 \\
\hline IG_VC1192 & 3 \\
\hline VC1192 & 2 \\
\hline IG_VC1191 & 3 \\
\hline VC1190 & 3 \\
\hline VC1181 & 2 \\
\hline VC1180 & 2 \\
\hline VC1174 & 2 \\
\hline VC1173 & 2 \\
\hline VC1172 & 2 \\
\hline VC1171 & 3 \\
\hline VC1170 & 2 \\
\hline
\end{tabular}

\begin{tabular}{|c|c|}
\hline VC1169 & 2 \\
\hline VC1166 & 2 \\
\hline IG_VC1159 & 2 \\
\hline VC1159 & 2 \\
\hline VC1149 & 2 \\
\hline VC1141 & 2 \\
\hline IG_VC1140 & 3 \\
\hline VC1139 & 3 \\
\hline VC1138 & 2 \\
\hline VC1137 & 2 \\
\hline VC1136 & 2 \\
\hline VC1135 & 2 \\
\hline VC1134 & 2 \\
\hline VC1133 & 2 \\
\hline VC1132 & 2 \\
\hline IG_VC1130 & 3 \\
\hline VC1130 & 2 \\
\hline VC1128 & 2 \\
\hline IG_VC1127 & 2 \\
\hline VC1127 & 2 \\
\hline IG_VC1126 & 2 \\
\hline VC1126 & 2 \\
\hline IG_VC1111 & 3 \\
\hline VC1110 & 2 \\
\hline VC1109 & 2 \\
\hline VC1107 & 2 \\
\hline IG_VC1072 & 2 \\
\hline VC1072 & 2 \\
\hline IG_VC1071 & 3 \\
\hline VC1068 & 3 \\
\hline IG_VC1067 & 3 \\
\hline VC1054 & 2 \\
\hline IG_VC1042 & 3 \\
\hline VC1036 & 2 \\
\hline VC1017 & 2 \\
\hline VC1016 & 2 \\
\hline VC1015 & 2 \\
\hline VC1014 & 2 \\
\hline VC1013 & 2 \\
\hline VC1012 & 2 \\
\hline IG_VC1004 & 2 \\
\hline VC1004 & 2 \\
\hline
\end{tabular}

\begin{tabular}{|c|c|}
\hline VC1002 & 3 \\
\hline VC1001 & 2 \\
\hline IG_VC1000 & 2 \\
\hline VC1000 & 2 \\
\hline VC0997 & 2 \\
\hline IG_VC0996 & 2 \\
\hline IG_VC0991 & 2 \\
\hline VC0991 & 2 \\
\hline VC0989 & 3 \\
\hline IG_VC0988 & 3 \\
\hline VC0987 & 2 \\
\hline VC0986 & 2 \\
\hline IG_VC0971 & 3 \\
\hline VC0971 & 2 \\
\hline IG_VC0970 & 3 \\
\hline VC0970 & 2 \\
\hline IG_VC0966 & 2 \\
\hline VC0966 & 2 \\
\hline IG_VC0965 & 2 \\
\hline VC0965 & 3 \\
\hline VC0963 & 2 \\
\hline IG_VC0961 & 3 \\
\hline VC0961 & 2 \\
\hline VC0960 & 2 \\
\hline VC0958 & 2 \\
\hline VC0956 & 2 \\
\hline VC0954 & 2 \\
\hline VC0953 & 2 \\
\hline VC0950 & 2 \\
\hline VC0949 & 2 \\
\hline VC0945 & 2 \\
\hline IG_VC0944 & 2 \\
\hline VC0944 & 2 \\
\hline Vco943 & 2 \\
\hline VC0941 & 2 \\
\hline VC0934 & 3 \\
\hline IG_VC0933 & 2 \\
\hline IG_VC0929 & 3 \\
\hline vc0929 & 3 \\
\hline IG_VC0928 & 2 \\
\hline IG_VC0927 & 2 \\
\hline VC0927 & 3 \\
\hline
\end{tabular}




\begin{tabular}{|c|c|}
\hline IG_VC0916 & 3 \\
\hline IG_VC0915 & 3 \\
\hline VC0890 & 2 \\
\hline IG_VC0889 & 2 \\
\hline VC0889 & 2 \\
\hline IG_VC0888 & 2 \\
\hline VC0875 & 2 \\
\hline VC0869 & 2 \\
\hline VC0868 & 3 \\
\hline VC0864 & 2 \\
\hline VC0856 & 2 \\
\hline IG_VC0855 & 3 \\
\hline VC0855 & 2 \\
\hline VC0854 & 2 \\
\hline IG_VC0853 & 2 \\
\hline VC0853 & 2 \\
\hline VC0850 & 2 \\
\hline VC0849 & 2 \\
\hline IG_VC0816 & 3 \\
\hline VC0814 & 2 \\
\hline IG_VC0813 & 3 \\
\hline IG_VC0811 & 2 \\
\hline VC0811 & 2 \\
\hline IG_VC0810 & 2 \\
\hline VC0810 & 2 \\
\hline VC0796 & 2 \\
\hline IG_VC0795 & 3 \\
\hline IG_VC0769 & 3 \\
\hline VC0768 & 2 \\
\hline IG_VC0767 & 2 \\
\hline VC0767 & 2 \\
\hline IG_VC0764 & 3 \\
\hline IG_VC0763 & 2 \\
\hline VC0763 & 2 \\
\hline IG_VC0762 & 2 \\
\hline VC0762 & 2 \\
\hline VC0760 & 2 \\
\hline IG_VC0759 & 2 \\
\hline VC0759 & 2 \\
\hline VC0758 & 3 \\
\hline VC0756 & 2 \\
\hline VC0753 & 3 \\
\hline
\end{tabular}

\begin{tabular}{|c|c|}
\hline VC0752 & 2 \\
\hline VC0751 & 2 \\
\hline IG_VC0750 & 2 \\
\hline VC0750 & 2 \\
\hline IG_VC0749 & 2 \\
\hline VC0749 & 2 \\
\hline IG_VC0748 & 2 \\
\hline VC0748 & 2 \\
\hline IG_VC0747 & 2 \\
\hline VC0747 & 3 \\
\hline VC0745 & 3 \\
\hline IG_VC0733 & 3 \\
\hline VC0733 & 3 \\
\hline VC0727 & 3 \\
\hline IG_VC0726 & 2 \\
\hline VC0726 & 2 \\
\hline VC0725 & 2 \\
\hline VC0724 & 2 \\
\hline VC0708 & 2 \\
\hline VC0705 & 2 \\
\hline IG_VC0704 & 3 \\
\hline VC0696 & 2 \\
\hline IG_VC0694 & 3 \\
\hline VC0685 & 2 \\
\hline VC0683 & 2 \\
\hline IG_VC0682 & 2 \\
\hline VC0682 & 2 \\
\hline IG_VC0681 & 2 \\
\hline VC0681 & 2 \\
\hline VC0680 & 2 \\
\hline IG_VC0679 & 3 \\
\hline VC0679 & 2 \\
\hline IG_VC0678 & 2 \\
\hline VC0675 & 2 \\
\hline IG_VC0674 & 2 \\
\hline VC0674 & 2 \\
\hline IG_VC0673 & 2 \\
\hline IG_VC0664 & 3 \\
\hline VC0664 & 2 \\
\hline IG_VC0662 & 2 \\
\hline IG_VC0661 & 3 \\
\hline VC0660 & 3 \\
\hline
\end{tabular}

\begin{tabular}{|c|c|}
\hline IG_VC0647 & 3 \\
\hline VC0647 & 2 \\
\hline IG_VC0646 & 3 \\
\hline VC0646 & 2 \\
\hline IG_VC0645 & 2 \\
\hline VC0644 & 3 \\
\hline VC0643 & 2 \\
\hline VC0642 & 2 \\
\hline VC0641 & 2 \\
\hline VCt047 & 2 \\
\hline VC0640 & 2 \\
\hline VC0639 & 2 \\
\hline IG_VC0638 & 2 \\
\hline VC0638 & 2 \\
\hline IG_VC0637 & 2 \\
\hline VC0637 & 2 \\
\hline IG_VC0636 & 3 \\
\hline IG_VC0633 & 3 \\
\hline IG_VC0631 & 2 \\
\hline VC0631 & 2 \\
\hline VC0627 & 2 \\
\hline VC0626 & 2 \\
\hline IG_VC0620 & 3 \\
\hline VC0604 & 2 \\
\hline IG_VC0603 & 3 \\
\hline VC0594 & 2 \\
\hline VC0593 & 2 \\
\hline VC0592 & 2 \\
\hline VC0591 & 2 \\
\hline VC0581 & 2 \\
\hline VC0576 & 2 \\
\hline VC0573 & 3 \\
\hline IG_VC0572 & 2 \\
\hline VC0572 & 2 \\
\hline VC0571 & 2 \\
\hline VC0570 & 2 \\
\hline IG_VC0569 & 2 \\
\hline VC0569 & 2 \\
\hline VC0565 & 2 \\
\hline IG_VC0564 & 2 \\
\hline VC0564 & 2 \\
\hline IG VC0563 & 2 \\
\hline
\end{tabular}

\begin{tabular}{|c|c|}
\hline VC0563 & 2 \\
\hline IG_VC0562 & 2 \\
\hline VC0562 & 2 \\
\hline IG_VC0561 & 2 \\
\hline VC0561 & 2 \\
\hline IG_VC0560 & 2 \\
\hline VC0560 & 2 \\
\hline IG_VC0559 & 3 \\
\hline VCt041 & 2 \\
\hline IG_VCt040 & 2 \\
\hline VCt040 & 2 \\
\hline IG_VCt039 & 2 \\
\hline VCt039 & 2 \\
\hline IG_VC0548 & 2 \\
\hline VC0548 & 2 \\
\hline IG_VC0547 & 3 \\
\hline VC0545 & 2 \\
\hline VC0541 & 2 \\
\hline VC0540 & 3 \\
\hline VC0539 & 3 \\
\hline IG_VC0529 & 3 \\
\hline VC0529 & 2 \\
\hline VC0528 & 2 \\
\hline VC0527 & 2 \\
\hline VC0524 & 2 \\
\hline IG_VC0520 & 3 \\
\hline VC0520 & 2 \\
\hline IG_VC0519 & 2 \\
\hline VC0519 & 2 \\
\hline IG_VC0517 & 2 \\
\hline VCt038 & 2 \\
\hline IG_VC0515 & 2 \\
\hline VC0515 & 2 \\
\hline IG_VC0514 & 2 \\
\hline VC0514 & 3 \\
\hline VC0513 & 3 \\
\hline IG_VC0512 & 3 \\
\hline VC0490 & 3 \\
\hline IG_VC0489 & 3 \\
\hline VC0487 & 2 \\
\hline IG_VC0486 & 3 \\
\hline VC0478 & 2 \\
\hline
\end{tabular}

\begin{tabular}{|c|c|}
\hline IG_VC0477 & 3 \\
\hline VC0477 & 2 \\
\hline IG_VC0476 & 2 \\
\hline VC0472 & 2 \\
\hline IG_VC0466 & 2 \\
\hline VC0466 & 2 \\
\hline IG_VC0460 & 2 \\
\hline VC0460 & 2 \\
\hline VC0446 & 2 \\
\hline IG_VC0445 & 2 \\
\hline VC0445 & 2 \\
\hline VC0444 & 2 \\
\hline VC0443 & 2 \\
\hline VC0440 & 2 \\
\hline VC0437 & 2 \\
\hline VC0436 & 2 \\
\hline IG_VC0435 & 2 \\
\hline VC0435 & 2 \\
\hline IG_VC0434 & 3 \\
\hline VC0434 & 2 \\
\hline IG_VC0423 & 3 \\
\hline VC0417 & 2 \\
\hline VC0416 & 2 \\
\hline IG_VC0415 & 2 \\
\hline VC0415 & 2 \\
\hline IG_VC0414 & 3 \\
\hline VC0397 & 2 \\
\hline IG_VC0396 & 3 \\
\hline VC0386 & 2 \\
\hline VC0385 & 2 \\
\hline VC0384 & 2 \\
\hline IG_VC0383 & 2 \\
\hline VC0374 & 3 \\
\hline VC0372 & 2 \\
\hline VC0371 & 2 \\
\hline VC0368 & 2 \\
\hline VC0367 & 2 \\
\hline VC0366 & 2 \\
\hline IG_VC0365 & 3 \\
\hline IG_VC0361 & 2 \\
\hline VC0361 & 2 \\
\hline IG_VC0360 & 2 \\
\hline
\end{tabular}




\begin{tabular}{|c|c|}
\hline Vc0360 & 2 \\
\hline IG_VC0359 & 2 \\
\hline VC0359 & 2 \\
\hline IG_VC0358 & 2 \\
\hline VC0358 & 2 \\
\hline Vc0357 & 2 \\
\hline VC0356 & 2 \\
\hline VC0344 & 3 \\
\hline VC0343 & 2 \\
\hline VC0341 & 2 \\
\hline IG_VC0340 & 3 \\
\hline VC0340 & 2 \\
\hline VC0339 & 2 \\
\hline IG_VC0336 & 3 \\
\hline VC0336 & 2 \\
\hline VC0332 & 2 \\
\hline VC0329 & 2 \\
\hline IG_VC0328 & 2 \\
\hline VC0328 & 2 \\
\hline IG_VC0327 & 2 \\
\hline VC0327 & 2 \\
\hline IG_VC0326 & 2 \\
\hline VC0326 & 2 \\
\hline IG_VC0325 & 2 \\
\hline VC0325 & 2 \\
\hline VC0324 & 2 \\
\hline IG_VC0323 & 2 \\
\hline VC0323 & 2 \\
\hline IG_VC0322 & 2 \\
\hline VC0322 & 2 \\
\hline IG_VC0321 & 2 \\
\hline VC0320 & 2 \\
\hline VC0319 & 2 \\
\hline VC0318 & 2 \\
\hline VC0315 & 2 \\
\hline VC0309 & 2 \\
\hline VC0307 & 2 \\
\hline
\end{tabular}

\begin{tabular}{|c|c|}
\hline VC0306 & 3 \\
\hline IG_VC0297 & 3 \\
\hline VC0297 & 2 \\
\hline VC0296 & 2 \\
\hline VC0295 & 2 \\
\hline IG_VC0276 & 2 \\
\hline VC0276 & 2 \\
\hline VC0275 & 3 \\
\hline VC0259 & 3 \\
\hline IG_VC0258 & 3 \\
\hline VC0258 & 3 \\
\hline VC0249 & 3 \\
\hline VC0248 & 2 \\
\hline IG_VC0247 & 2 \\
\hline VC0247 & 2 \\
\hline VC0246 & 3 \\
\hline VC0238 & 3 \\
\hline VC0237 & 3 \\
\hline VC0236 & 3 \\
\hline VC0233 & 2 \\
\hline VC0228 & 3 \\
\hline VC0227 & 2 \\
\hline VC0226 & 2 \\
\hline VC0225 & 2 \\
\hline VC0222 & 2 \\
\hline VC0219 & 2 \\
\hline VC0218 & 2 \\
\hline IG_VC0217 & 3 \\
\hline VC0215 & 2 \\
\hline VC0213 & 2 \\
\hline VC0211 & 3 \\
\hline IG_VC0175 & 3 \\
\hline IG_VC0168 & 3 \\
\hline VC0167 & 2 \\
\hline VC0162 & 2 \\
\hline VC2755 & 2 \\
\hline VC2762 & 2 \\
\hline
\end{tabular}

\begin{tabular}{|l|l|}
\hline VC2763 & 2 \\
\hline VC2764 & 2 \\
\hline IG_VC2765 & 2 \\
\hline VC2765 & 2 \\
\hline IG_VC2766 & 2 \\
\hline VC2766 & 2 \\
\hline VC2767 & 2 \\
\hline VC2768 & 2 \\
\hline IG_VC2769 & 2 \\
\hline VC2769 & 2 \\
\hline IG_VC2770 & 2 \\
\hline VC2770 & 2 \\
\hline VC2771 & 2 \\
\hline VC2775 & 2 \\
\hline IG_VCA0001 & 2 \\
\hline VCA0001 & 3 \\
\hline IG_VCA0002 & 2 \\
\hline VCA0002 & 2 \\
\hline VCA0016 & 2 \\
\hline VCA0021 & 2 \\
\hline VCA0040 & 2 \\
\hline IG_VCA0061 & 2 \\
\hline VCA0061 & 2 \\
\hline VCA0079 & 3 \\
\hline VCA0093 & 3 \\
\hline IG_VCA0094 & 2 \\
\hline VCA0094 & 2 \\
\hline IG_VCA0095 & 2 \\
\hline VCA0095 & 3 \\
\hline IG_VCA0105 & 3 \\
\hline VCA0106 & 3 \\
\hline VCA0124 & 2 \\
\hline IG_VCA0125 & 2 \\
\hline IG_VCA0143 & 2 \\
\hline
\end{tabular}

\begin{tabular}{|c|c|}
\hline VCA0162 & 2 \\
\hline VCA0198 & 2 \\
\hline VCA0199 & 3 \\
\hline VCA0200 & 3 \\
\hline VCA0201 & 3 \\
\hline IG_VCA0202 & 3 \\
\hline VCA0207 & 2 \\
\hline IG_VCA0208 & 2 \\
\hline VCA0208 & 2 \\
\hline IG_VCA0219 & 3 \\
\hline IG_VCA0247 & 2 \\
\hline IG_VCA0287 & 3 \\
\hline VCA0287 & 2 \\
\hline IG_VCA0289 & 2 \\
\hline VCA0289 & 2 \\
\hline IG_VCA0290 & 2 \\
\hline VCA0290 & 2 \\
\hline $\begin{array}{l}\text { IG_Int|4- } \\
\text { VCA0291 }\end{array}$ & 3 \\
\hline VCA0324 & 3 \\
\hline IG_VCA0325 & 3 \\
\hline VCA0333 & 2 \\
\hline IG_VCA0334 & 2 \\
\hline VCA0334 & 2 \\
\hline VCA0360 & 2 \\
\hline VCA0363 & 2 \\
\hline IG_VCA0392 & 2 \\
\hline VCA0392 & 2 \\
\hline IG_VCA0477 & 3 \\
\hline VCA0477 & 2 \\
\hline VCA0486 & 2 \\
\hline VCA0488 & 2 \\
\hline VCA0498 & 3 \\
\hline IG_VCA0524 & 3 \\
\hline VCA0524 & 3 \\
\hline VCA0528 & 2 \\
\hline IG_VCA0570 & 3 \\
\hline VCA0572 & 2 \\
\hline
\end{tabular}

\begin{tabular}{|l|l|}
\hline IG_VCA0576 & 3 \\
\hline VCA0614 & 3 \\
\hline VCA0616 & 2 \\
\hline VCA0628 & 2 \\
\hline IG_VCA0643 & 2 \\
\hline VCA0643 & 3 \\
\hline IG_VCA0669 & 3 \\
\hline VCA0669 & 3 \\
\hline IG_VCA0693 & 3 \\
\hline IG_VCA0701 & 2 \\
\hline VCA0701 & 2 \\
\hline IG_VCA0702 & 3 \\
\hline IG_VCA0786 & 3 \\
\hline VCA0786 & 2 \\
\hline IG_VCA0812 & 3 \\
\hline IG_VCA0834 & 2 \\
\hline VCA0834 & 3 \\
\hline IG_VCA0874 & 3 \\
\hline VCA0874 & 3 \\
\hline VCA0921 & 2 \\
\hline VCA0925 & 2 \\
\hline VCA0934 & 3 \\
\hline IG_VCA0935 & 3 \\
\hline IG_VCA0952 & 3 \\
\hline VCA0952 & 2 \\
\hline IG_VCA0953 & 3 \\
\hline IG_VCA0975 & 3 \\
\hline IG_VCA1037 & 3 \\
\hline VCA1044 & 3 \\
\hline IG_VCA1064 & 2 \\
\hline VCA1064 & 3 \\
\hline VCA1079 & 2 \\
\hline IG_VCA1114 & 2 \\
\hline VCA114 & 2 \\
\hline IG & 2 \\
\hline
\end{tabular}

